\title{
Design, synthesis and evaluation of anticancer activity of novel 2-thioxoimidazolidin-4-one derivatives bearing pyrazole, triazole and benzoxazole moieties
}

\author{
Heba A. Elhady ${ }^{1,2^{*}}$, Refat El-Sayed ${ }^{1,3}$ and Hamedah S. Al-nathali ${ }^{1}$
}

\begin{abstract}
A novel series of substituted 2-thiohydantoin incorporated with benzoimidazole, pyrazole, triazole and/or benzoxazole moieties has been synthesized using (E)-3-[1-(4-bromophenyl)ethylideneamino]-2-thioxoimidazolidin-4-one $\mathbf{1}$ as the key starting material. The key material $\mathbf{1}$ also, reacted with an acetic anhydride, aromatic aldehydes, secondary amines, formaldehyde and triethyl orthoformate to give the corresponding acetyl, chalcone, Mannich bases and ethoxymethylene derivatives, respectively. The structures of the novel compounds were confirmed by spectral data and elemental analysis. The cytotoxic activity of all synthesized compounds was assessed in vitro against human hepatocellular cancer cell line (HePG-2) and breast carcinoma cell line (MCF-7). The bioassay results revealed that compound $1 \mathbf{4}$ has the best activity against $\mathrm{HePG}-2$ cell line $\left(\mathrm{IC}_{50}=2.33 \mu \mathrm{g} / \mathrm{mL}\right)$, while compound $\mathbf{5}$ has the best activity against MCF-7 cell line $\left(\mathrm{IC}_{50}=3.98 \mathrm{\mu g} / \mathrm{mL}\right)$.
\end{abstract}

Keywords: 2-Thiohydantoin, Benzoimidazole, Benzoxazole, Pyrazole, HEPG-2 cell line and MCF-7 cell line

\section{Introduction}

2-Thioxoimidazolidin-4-one ring (2-thiohydantoin) has been extensively studied. This five-membered heterocyclic ring is present in a wide range of biologically active compounds. The biological activities have been shown by some of their derivatives are mainly, anticonvulsant [1], antiviral [2], antiproliferative [3], anticancer [4-9], antibacterial, antifungal [10], anxiolytic [11], antidiabetic activity [12] and also used as inhibitor of a fatty acid amide hydrolase [13]. Additionally, 2-thiohydantoins are used in synthetic chemistry as in skin hyperpigmentation applications [14], in the production of antimicrobial polyurethane coatings [15], in textile printing, polymerization catalysis [16] and as a reagent for development of dyes [17]. The observed activities arise from the thiohydantoin heterocycle, but the different substituents attached to it

\footnotetext{
*Correspondence: hebaa_elhady@yahoo.com

1 Department of Chemistry, Faculty of Applied Sciences, Umm Al-Qura

University, P. O. Box 13401, Makkah 21955, Saudi Arabia

Full list of author information is available at the end of the article
}

are determinant in these properties. Diverse applications of 2-thioxoimidazolidin-4-one in drug field have encouraged the medicinal chemists to synthesize and evaluate a large number of novel molecules. In this research point, we design new compounds based on the biological activity of other heterocycles such as pyrazoles [18, 19], triazoles [20, 21], benzimidazole [22], benzoxazole [23] and Schiff bases [24-26] in the field of cancer and microbial therapy. As an extension of our work on the synthesis of heterocyclic systems and evaluation of their biological activity [27-33], we reported here the synthesis of some novel substituted 2-thiohydantoin and evaluate their cytotoxic activity. (E)-3-[1-(4-bromophenyl) ethylideneamino]-2-thioxoimidazolidin-4-one 1 was prepared and used as the building block for the synthesis of the novel compounds.

\section{Results and discussion Chemistry}

As an extension of our interest on the chemistry of 2-thiohydantoin, we reported here the synthesis of 
novel derivatives using (E)-3-[1-(4-bromophenyl) ethylideneamino]-2-thioxoimidazolidin-4-one $\mathbf{1}$ as the key starting material. Compound $\mathbf{1}$ was prepared via reaction of (E)-2-[1-(4-bromophenyl)ethylidene]hydrazinecarbothioamide in the presence of sodium acetate $[27,28]$. Alkylation of $\mathbf{1}$ with ethyl chloroacetate in the presence of anhydrous potassium carbonate gave $(E)$ ethyl 2-\{3-[1-(4-bromophenyl)ethylideneamino]-4-oxo2-thioxoimidazolidin-1-yl\}acetate 2 . The structure of 2 was confirmed by spectral data, elemental analysis and chemical transformation. Thus, hydrolysis of the ester $\mathbf{2}$ with $2 \mathrm{~N}$ sodium hydroxide gave $(E)-2$-\{3-[1-(4-bromophenyl)ethylideneamino]-4-oxo-2-thioxoimidazolidin1-yl\}acetic acid 3. Hydrazinolysis of 2 with hydrazine hydrate in ethanol gave (E)-2-\{3-[1-(4-bromophenyl) ethylideneamino]-4-oxo-2-thioxoimidazolidin-1-yl\}acetohydrazide 4, which is a suitable intermediate for the synthesis of the target compounds (Scheme 1). Cyclization of $\mathbf{4}$ with ethyl acetoacetate, acetylacetone and/or ethyl cyanoacetate in acetic acid gave the corresponding pyrazole derivatives 5, 6 and pyrazole-3,5-dione derivative 7 , respectively. Also, reaction of 4 with ethoxymethylenemalononitrile (EMM) in ethanol under reflux gave pyrazole-4-carbonitrile derivative $\mathbf{8}$ (Scheme 2).

To obtain a series of biologically active compounds, compound $\mathbf{4}$ was treated with phenylisothiocyanate in dimethylformamide to afford 9, which cyclized with $5 \%$ alcoholic sodium hydroxide to give 4-phenyl-5-thioxo-1,2,4-triazole derivative 10. Moreover, condensation of $\mathbf{4}$ with different aromatic aldehydes namely, isonicotinaldehyde and 4-hydroxy-3-methoxybenzaldehyde in ethanol in the presence of piperidine under reflux led to the formation of Schiff bases 11a, b (Scheme 3).

To obtain substituted 2-thiohydantoin derivatives incorporated with benzoimidazole and/or benzoxazole moieties, compound $\mathbf{1}$ was reacted with triethyl orthoformate and/or diethyl oxalate in xylene in the presence of sodium metal under reflux to give 12 and/or 13, respectively. Compound 13 was condensed with $o$-phenylenediamine and/or 2-aminophenol in acetic acid under fusion to give $\mathbf{1 4}$ and/or 15, respectively (Scheme 4). Morover, new series of biologically active 2-thiohydantoin derivatives were prepared by acetylation of $\mathbf{1}$ with acetic anhydride to give $\mathbf{1 6}$ and 17. Condensation of $\mathbf{1 6}$ with aldehydes such as vanillin in the presence of piperidine under fusion gave chalcone derivative 18. Also, Mannich base was prepared by reacting 1 with diethylamine and formaldehyde in ethanol to give 19. Finally, hydrazinolysis of $\mathbf{1}$ with hydrazine hydrate in ethanol gave 20 (Scheme 5). The structures of the synthesized compounds were confirmed by spectral data and elemental analysis.

\section{Biological assessment}

\section{In vitro anticancer screening}

The anti-tumor activity of all synthesized compounds has been evaluated against two cell lines HepG-2 cells (human hepatocellular cancer cell line), and MCF-7 (breast carcinoma cell line) [34-36]. The cell lines were obtained from VACSERA Tissue Culture Unit, and the experiments were performed by the Regional Center for Mycology and Biotechnology, Al-Azhar University, Cairo, Egypt. Different concentrations of the tested samples $(500,250,125,62.5,31.25,15.6,7.8,3.9,2$ and $1 \mu \mathrm{g} / \mathrm{mL}$ ) were used to detect the inhibitory activity. Cell viability (\%) was determined by colorimetric method. Doxorubicin was used as the reference drug, as it is one of the most effective anticancer agents. The relationship between drug concentration and cell viability was plotted to obtain the survival curve of hepatocellular carcinoma cell line HePG2 and breast cancer cell line MCF-7. The $\mathrm{IC}_{50}$ value, which corresponds to the concentration required for $50 \%$ inhibition of cell viability was calculated.

Tables 1, 2, 3 show the in vitro cytotoxicity of the synthesized compounds against hepatocellular carcinoma cell line HePG-2. Tables 4, 5, 6 show the in vitro cytotoxicity against breast carcinoma cell line MCF-7. Data examination revealed that the tested compounds showed good to moderate activity. Compound $\mathbf{1 4}$ has the best activity against HePG-2 cell line $\left(\mathrm{IC}_{50}=2.33 \mu \mathrm{g} / \mathrm{mL}\right)$, while, compound $\mathbf{5}$ has the best activity against MCF-7 cell line $\left(\mathrm{IC}_{50}=3.98 \mu \mathrm{g} / \mathrm{mL}\right)$ and compound 11a has the lowest activity against HePG-2 cell line $\left(\mathrm{IC}_{50}=243 \mu \mathrm{g} /\right.$ $\mathrm{mL})$ and against MCF-7 cell line $\left(\mathrm{IC}_{50}=249 \mu \mathrm{g} / \mathrm{mL}\right)$. The structure and biological activity relationship of the title compound 1 showed that, the activity of thiohydantoin diverse with the substituents on it, where introducing active groups such as, $\mathrm{CH}_{3} \mathrm{CO}, \mathrm{OH}, \mathrm{OCH}_{3}, \mathrm{OC}_{2} \mathrm{H}_{5}$, $=\mathrm{CH}-\mathrm{OC}_{2} \mathrm{H}_{5}$ enhanced the activity, also, the presence of benzoimidazole, pyrazolone, pyrazole carbonitrile and triazine moieties enhanced the activity of thiohydantoin, while the activity was decreased by introducing benzoxazole, pyrazolidinedione moieties and Schiff bases. Alkylation of thiohydantoin decreases the activity; however, when the ester $\mathbf{2}$ was reacted with hydrazine hydrate to form the acid hydrazide $\mathbf{4}$ the activity was enhanced especially against MCF-7 cell line.

The resulting data of the $50 \%$ inhibition concentration $\left(\mathrm{IC}_{50}\right)$ summarized in Table 7 showed that, the synthesized compounds have different activity against hepatocellular carcinoma cell line HePG2 and breast cancer cell line MCF-7. 


\section{Conclusion}

A novel series of substituted 2-thiohydantoin with incorporated benzoimidazole, pyrazole, triazole and/ or benzoxazole moieties has been synthesized. The structures of these compounds were confirmed by IR, ${ }^{1}$ HNMR, ${ }^{13}$ CNMR, MS and elemental analysis. The bioassay results revealed that, Compound $\mathbf{1 4}$ has the best activity against $\mathrm{HePG} 2$ cell line $\left(\mathrm{IC}_{50}=2.33 \mu \mathrm{g} / \mathrm{mL}\right)$, while compound 5 has the best activity against MCF-7 cell line $\left(\mathrm{IC}_{50}=3.98 \mu \mathrm{g} / \mathrm{mL}\right)$. Structure and biological activity relationship showed that, the activity of thiohydantoin diverse with the substituents on it, where introducing active groups such as, $\mathrm{CH}_{3} \mathrm{CO}, \mathrm{OH}, \mathrm{OCH}_{3}$, $\mathrm{OC}_{2} \mathrm{H}_{5},=\mathrm{CH}-\mathrm{OC}_{2} \mathrm{H}_{5}$ and the presence of benzoimidazole, pyrazolone, pyrazole carbonitrile and triazine moieties enhanced the activity of thiohydantoin.<smiles>CCOC(=O)CN1CC(=O)N(/N=C(\C)c2ccc(Br)cc2)C1=S</smiles>

Scheme 1 Synthesis of compounds $\mathbf{2 , 3}$ and $\mathbf{4}$

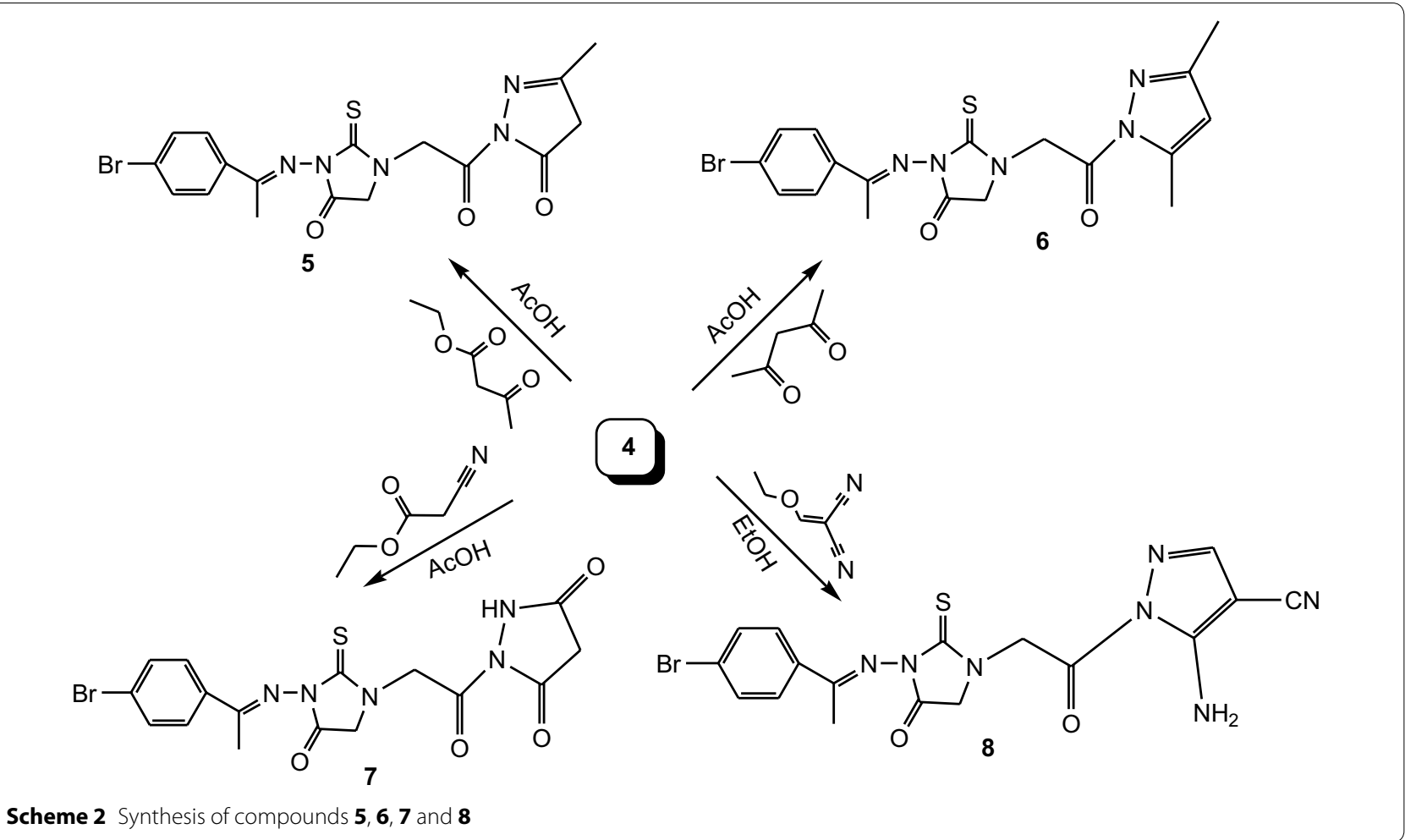




\section{Experimental section}

Melting points were measured using electrothermal digital melting points apparatus and are uncorrected. IR (infrared) spectra were recorded on NICOLET (iS50 FT-IR) spectrometer using $\mathrm{KBr}$ pellets. ${ }^{1} \mathrm{H}$ and ${ }^{13} \mathrm{C}$ NMR (nuclear magnetic resonance) were recorded on a Bruker AS $850 \mathrm{TM}$ spectrometer at $850 \mathrm{MHz}$ and chemical shifts were given with respect to TMS (tetramethylsilane). Mass (MS) spectra were recorded on GC/MS with CI (chemical ionization) and a Hewlett-Packard MS Engine Thermospray and ionization by electron impact to $(70 \mathrm{eV})$. Microanalysis was conducted using elemental analyzer 106.

Synthesis of (E)-3-[1-(4-bromophenyl)ethylideneamino]-2thioxoimidazolidin-4-one 1 A mixture of (E)-2-[1(4-bromophenyl)ethylidene]hydrazinecarbothioamide $(0.01 \mathrm{~mol})$ and ethyl chloroacetate $(0.01 \mathrm{~mol})$ in ethanol $(50 \mathrm{~mL})$ in the presence of fused sodium acetate $(0.03 \mathrm{~mol})$ was heated under reflux for $2 \mathrm{~h}$, then cooled and poured into water. The solid formed was filtered off, washed with water, dried and purified from ethanol to give 1.

\section{Synthesis of (E)-ethyl 2-\{3-[1-(4-bromophenyl)} ethylideneamino]-4-oxo-2-thioxoimidazolidin-1-yl\}acetate 2

A mixture of $1(0.01 \mathrm{~mol})$, ethyl chloroacetate $(0.01 \mathrm{~mol})$ and anhydrous potassium carbonate $(0.015 \mathrm{~mol})$ in
$20 \mathrm{~mL}$ ethanol was stirred under reflux for $6 \mathrm{~h}$. The reaction mixture was poured into an ice-water mixture. The solid product separated was filtered off, washed with water, dried and crystallized from ethanol to give $\mathbf{2}$ as pale yellow crystals, in yield $92 \%$, m.p $78-80{ }^{\circ} \mathrm{C}$. ${ }^{1} \mathrm{H}-\mathrm{NMR}$ $\left(\mathrm{DMSO}-d_{6}\right): \delta=7.79(\mathrm{~d}, 2 \mathrm{H}, J=8.5 \mathrm{~Hz}, 2 \mathrm{CH}), 7.65(\mathrm{~d}$, $2 \mathrm{H}, J=8.5 \mathrm{~Hz}, 2 \mathrm{H}, 2 \mathrm{CH}), 4.52\left(\mathrm{~s}, 2 \mathrm{H}, \mathrm{CH}_{2}\right), 4.16(\mathrm{q}, 2 \mathrm{H}$, $\left.J=6.8 \mathrm{~Hz}, \mathrm{CH}_{2}\right), 4.10\left(\mathrm{~s}, 2 \mathrm{H}, \mathrm{CH}_{2}\right), 2.34\left(\mathrm{~s}, 3 \mathrm{H}, \mathrm{CH}_{3}\right)$ and $1.20\left(\mathrm{t}, 3 \mathrm{H}, J=6.8 \mathrm{~Hz}, \mathrm{CH}_{3}\right)$ ppm. ${ }^{13} \mathrm{C}-\mathrm{NMR}$ (DMSO- $\left.d_{6}\right)$ : $\delta=171.68(\mathrm{C}=\mathrm{S}), 166.96,162.10(2 \mathrm{C}=\mathrm{O}), 161.40(\mathrm{C}=\mathrm{N})$, $136.65,131.46,128.48,123.66$ (C-aromatic), $61.23\left(\mathrm{CH}_{2}\right)$, 58.94 $\left(\mathrm{CH}_{2}\right), 32.11\left(\mathrm{CH}_{2}\right), 14.33\left(\mathrm{CH}_{3}\right)$ and $14.24\left(\mathrm{CH}_{3}\right)$ ppm. IR (KBr): 1742, $1711(2 \mathrm{C}=\mathrm{O}), 1611(\mathrm{C}=\mathrm{N})$ and $1386(\mathrm{C}=\mathrm{S}) \mathrm{cm}^{-1}$. MS: $\mathrm{m} / \mathrm{z}(\%): 398(31), 397\left(\mathrm{M}^{+},{ }^{79} \mathrm{Br}\right.$, $100)$ and $399\left(\mathrm{M}^{+},{ }^{81} \mathrm{Br}, 80\right)$. Anal. Calcd. $\mathrm{C}_{15} \mathrm{H}_{16} \mathrm{BrN}_{3} \mathrm{O}_{3} \mathrm{~S}$ (398.27): C, 45.24; H, 4.05; Br, 20.06; N, 10.55; S, 8.05;. Found. C, 45.30; H, 4.11; Br, 19.97; N, 10.47; S, 8.10.

\section{Synthesis of (E)-2-\{3-[1-(4-bromophenyl)}

ethylideneamino]-4-oxo-2-thioxoimidazolidin-1-yl\}acetic acid 3

Sodium hydroxide $(30 \mathrm{~mL} / 4 \mathrm{~N})$ was added to a solution of $2(0.01 \mathrm{~mol})$ in ethanol $(30 \mathrm{~mL})$, then heated under reflux for $2 \mathrm{~h}$. The reaction mixture was cooled and acidified with $2 \mathrm{~N}$ hydrochloric acid. The solid formed was filtered off, washed with water, dried and purified from ethanol to give 3 as pale yellow crystals, in yield 52\%, m.p 213-215 ${ }^{\circ} \mathrm{C}$. ${ }^{1} \mathrm{H}-\mathrm{NMR}$ (DMSO- $d_{6}$ ): $\delta=9.37$ (br. s, $1 \mathrm{H}$, $\mathrm{OH}), 7.70(\mathrm{~d}, 2 \mathrm{H}, J=8.5 \mathrm{~Hz}, 2 \mathrm{CH}), 7.57(\mathrm{~d}, 2 \mathrm{H}, J=8.5 \mathrm{~Hz}$, $2 \mathrm{CH}), 4.53\left(\mathrm{~s}, 2 \mathrm{H}, \mathrm{CH}_{2}\right), 3.83\left(\mathrm{~s}, 2 \mathrm{H}, \mathrm{CH}_{2}\right)$ and $2.28(\mathrm{~s}$,

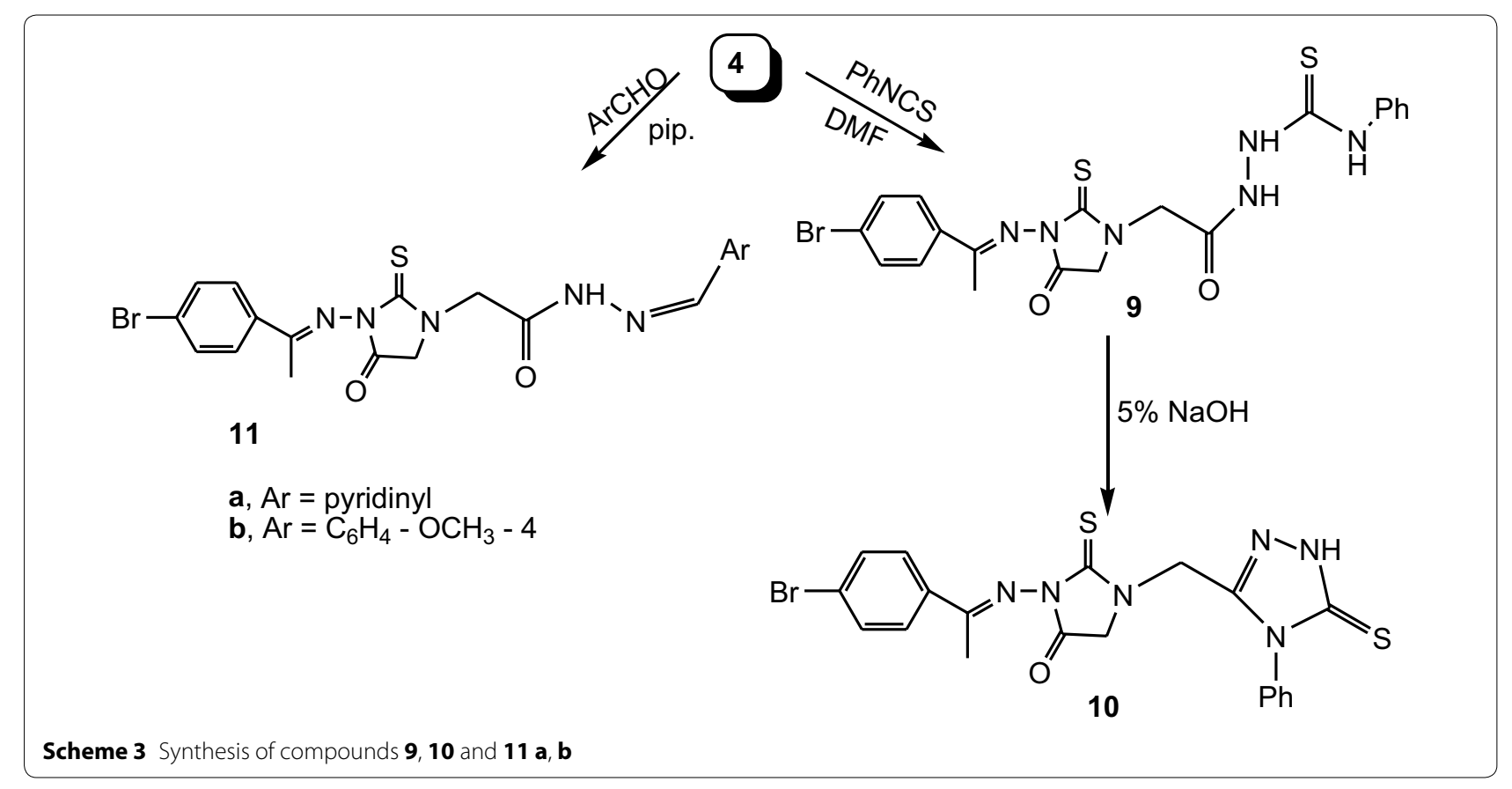


<smiles>CCO/C=C1/NC(=S)N(/N=C(\C)c2ccc(Br)cc2)C1=O</smiles>

12

15<smiles>C/C(=N\N1C(=O)C(C(=O)c2nc3ccccc3o2)NC1=S)c1ccc(Br)cc1</smiles>

Scheme 4 Synthesis of compounds 12, 13, 14 and 15 $\left.3 \mathrm{H}, \mathrm{CH}_{3}\right)$ ppm. ${ }^{13} \mathrm{C}-\mathrm{NMR}\left(\mathrm{DMSO}-d_{6}\right): \delta=173.45(\mathrm{C}=\mathrm{S})$, 168.83, $165.20(2 \mathrm{C}=\mathrm{O}), 157.19(\mathrm{C}=\mathrm{N}), 131.77,130.78$, 128.70, 126.03 (C-aromatic), $75.1\left(\mathrm{CH}_{2}\right), 29.81\left(\mathrm{CH}_{2}\right)$ and $14.03\left(\mathrm{CH}_{3}\right)$ ppm. IR (KBr): 3308 (br. $\left.\mathrm{OH}\right), 1725,1675$ $(2 \mathrm{C}=\mathrm{O}), 1617(\mathrm{C}=\mathrm{N})$ and $1393(\mathrm{C}=\mathrm{S}) \mathrm{cm}^{-1}$. MS: $\mathrm{m} / \mathrm{z}$ (\%): 370 (4), $369\left(\mathrm{M}^{+},{ }^{79} \mathrm{Br}, 14\right), 371\left(\mathrm{M}^{+},{ }^{81} \mathrm{Br}, 1\right), 368$ $\left(\mathrm{M}^{+}-1,34\right)$ and 57 (100). Anal. Calcd. $\mathrm{C}_{13} \mathrm{H}_{13} \mathrm{BrN}_{3} \mathrm{O}_{3} \mathrm{~S}$ (370.22): C, 42.17; H, 3.27; Br, 21.58; N, 11.35; S, 8.66;. Found. C, 42.27; H, 3.29; Br, 21.71; N, 11.48; S, 8.59.

\section{Synthesis of (E)-2-\{3-[1-(4-bromophenyl)} ethylideneamino]-4-oxo-2-thioxoimidazolidin-1-yl\}acetohydrazide 4

A mixture of $3(0.01 \mathrm{~mol})$ and hydrazine hydrate $(0.03 \mathrm{~mol})$ in ethanol $(20 \mathrm{~mL})$, was heated under reflux for $2 \mathrm{~h}$, the reaction mixture was cooled, then poured into ice/water solution and acidified with hydrochloric acid $(1 \mathrm{~N})$. The resulting solid was filtered off, washed with water, dried and crystallized from ethanol to give $\mathbf{4}$ as white crystals, in yield $85 \%$, m.p $196-198{ }^{\circ} \mathrm{C} .{ }^{1} \mathrm{H}-\mathrm{NMR}$ $\left(\mathrm{DMSO}-d_{6}\right): \delta=10.25(\mathrm{~s}, 1 \mathrm{H}, \mathrm{NH}), 8.30\left(\mathrm{~s}, 2 \mathrm{H}, \mathrm{NH}_{2}\right)$, $7.90(\mathrm{~d}, 2 \mathrm{H}, J=8.5 \mathrm{~Hz}, 2 \mathrm{CH}), 7.78(\mathrm{~d}, 2 \mathrm{H}, J=8.5 \mathrm{~Hz}$, $2 \mathrm{CH}), 4.43\left(\mathrm{~s}, 2 \mathrm{H}, \mathrm{CH}_{2}\right), 4.07\left(\mathrm{~s}, 2 \mathrm{H}, \mathrm{CH}_{2}\right)$ and $2.35(\mathrm{~s}$, $\left.3 \mathrm{H}, \mathrm{CH}_{3}\right)$ ppm. ${ }^{13} \mathrm{C}-\mathrm{NMR}\left(\mathrm{DMSO}-d_{6}\right): \delta=171.67(\mathrm{C}=\mathrm{S})$, 166.96, $165.43(2 \mathrm{C}=\mathrm{O}), 161.36(\mathrm{C}=\mathrm{N}), 136.69,131.45$, $128.44,123.67$ (C-aromatic), 61.28, $44.32\left(2 \mathrm{CH}_{2}\right)$, and $14.38\left(\mathrm{CH}_{3}\right)$. IR $(\mathrm{KBr}): 3407(\mathrm{NH}), 3225,3190\left(\mathrm{NH}_{2}\right)$, 1716, $1669(2 \mathrm{C}=\mathrm{O}), 1584(\mathrm{C}=\mathrm{N})$ and $1393(\mathrm{C}=\mathrm{S}) \mathrm{cm}^{-1}$. MS: $\mathrm{m} / \mathrm{z}$ (\%): $384(34), 383\left(\mathrm{M}^{+},{ }^{79} \mathrm{Br}, 5\right), 385\left(\mathrm{M}^{+},{ }^{81} \mathrm{Br}\right.$, $15)$ and 381 (100). Anal. Calcd. $\mathrm{C}_{13} \mathrm{H}_{14} \mathrm{BrN}_{5} \mathrm{O}_{2} \mathrm{~S}$ (384.25): C, 40.63; H, 3.67; Br, 20.79; N, 18.23; S, 8.34;. Found. C, 40.69; H, 3.56; Br, 20.75; N, 18.35; S, 8.27.

\section{Typical procedure for syntheses of compounds 5-7}

A mixture of compound $4(0.01 \mathrm{~mol})$ and an equimolar amount of ethyl acetoacetate or acetylacetone or ethyl cyanoacetate (or diethyl malonate) was refluxed in $10 \mathrm{~mL}$ of acetic acid for $5 \mathrm{~h}$. The product formed after cooling was filtered off, washed with water, dried and crystallized with acetic acid to give compounds 5, 6, and 7, respectively. 


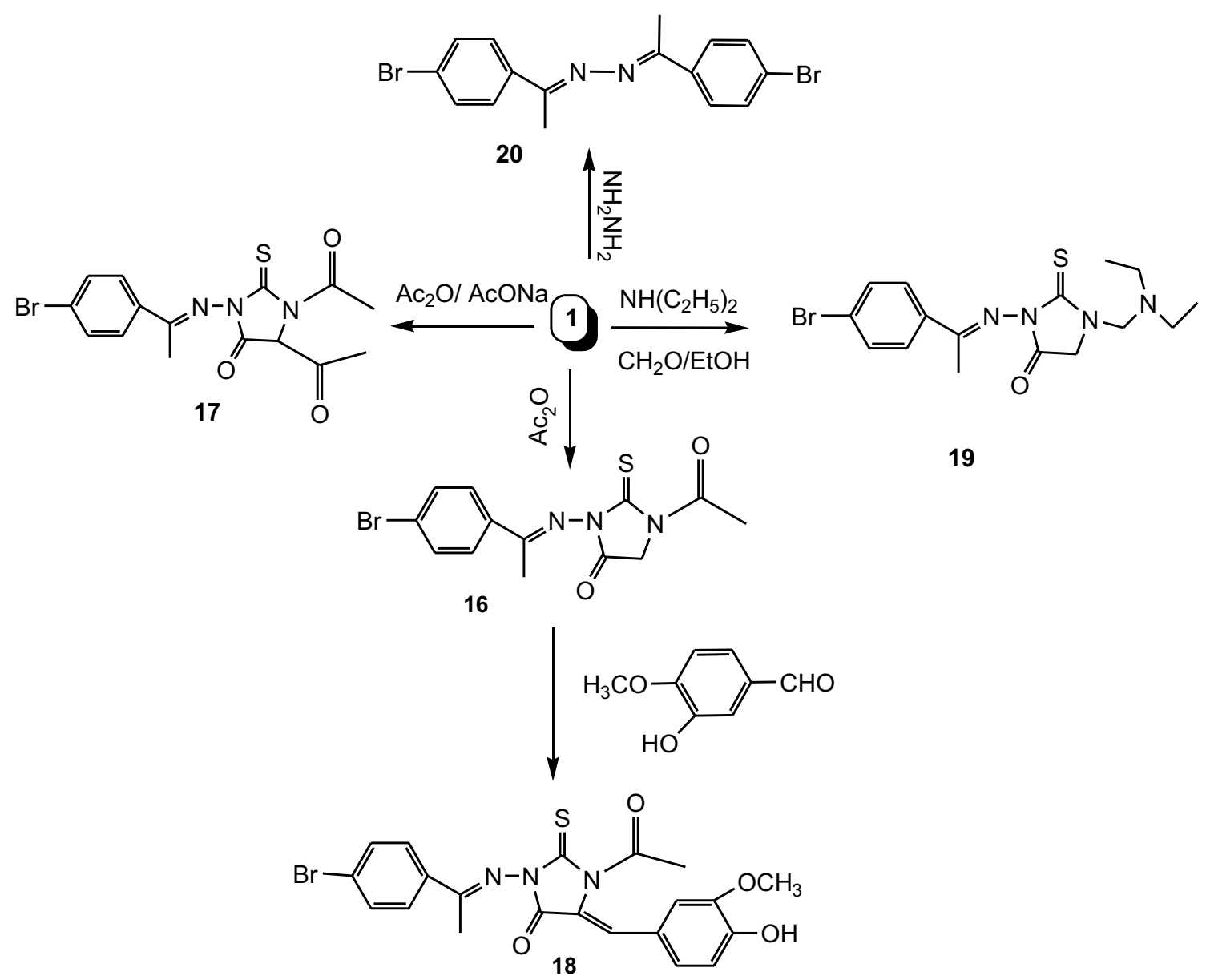

Scheme 5 Synthesis of compounds 16, 17, 18, 19 and 20

Table 1 Cytotoxicity of compounds 1, 2, 3, 4, 5, 6, 7 and 8 against hepatocellular carcinoma cell line HePG2

\begin{tabular}{|c|c|c|c|c|c|c|c|c|}
\hline \multirow[t]{2}{*}{ Concentration $\mu \mathrm{g} / \mathrm{mL}$} & \multicolumn{8}{|c|}{ Viability (\%)/compound } \\
\hline & 1 & 2 & 3 & 4 & 5 & 6 & 7 & 8 \\
\hline 500 & 5.26 & 19.86 & 2.97 & 7.48 & 3.04 & 31.67 & 12.58 & 6.31 \\
\hline 250 & 10.68 & 28.74 & 7.28 & 14.53 & 6.31 & 46.23 & 20.64 & 14.96 \\
\hline 125 & 18.97 & 39.45 & 11.49 & 21.84 & 10.25 & 68.92 & 31.75 & 20.85 \\
\hline 62.5 & 25.14 & 68.17 & 16.85 & 29.41 & 16.43 & 83.64 & 42.31 & 26.43 \\
\hline 31.25 & 34.72 & 79.52 & 23.72 & 38.63 & 22.37 & 93.51 & 64.15 & 38.14 \\
\hline 15.6 & 48.25 & 91.43 & 30.85 & 49.56 & 30.69 & 99.48 & 79.27 & 47.59 \\
\hline 7.8 & 62.89 & 98.76 & 41.93 & 71.38 & 38.15 & 100 & 88.74 & 60.31 \\
\hline 3.9 & 78.03 & 100 & 51.58 & 85.97 & 46.36 & 100 & 96.13 & 73.86 \\
\hline 2 & 86.26 & 100 & 62.72 & 92.04 & 59.02 & 100 & 99.47 & 85.23 \\
\hline 1 & 90.41 & 100 & 70.88 & 97.13 & 74.15 & 100 & 100 & 90.67 \\
\hline 0 & 100 & 100 & 100 & 100 & 100 & 100 & 100 & 100 \\
\hline
\end{tabular}


Table 2 Cytotoxicity of compounds 9, 10, 11a, 11b, 12, 13, and 14 against hepatocellular carcinoma cell line HePG2

\begin{tabular}{|c|c|c|c|c|c|c|c|}
\hline \multirow[t]{2}{*}{ Concentration $\mu \mathrm{g} / \mathrm{mL}$} & \multicolumn{7}{|c|}{ Viability (\%)/compound } \\
\hline & 9 & 10 & $11 a$ & $11 b$ & 12 & 13 & 14 \\
\hline 500 & 8.43 & 8.32 & 23.84 & 10.32 & 4.29 & 4.83 & 3.74 \\
\hline 250 & 15.82 & 16.01 & 48.67 & 19.47 & 11.82 & 12.56 & 8.91 \\
\hline 125 & 24.67 & 23.65 & 72.89 & 27.93 & 20.49 & 19.74 & 14.82 \\
\hline 62.5 & 30.93 & 29.86 & 90.31 & 38.76 & 26.54 & 28.63 & 20.94 \\
\hline 31.25 & 41.28 & 37.40 & 98.16 & 50.37 & 32.75 & 35.16 & 25.86 \\
\hline 15.6 & 48.71 & 46.89 & 100 & 68.24 & 41.87 & 46.29 & 31.43 \\
\hline 7.8 & 62.39 & 58.62 & 100 & 81.49 & 55.46 & 57.18 & 37.82 \\
\hline 3.9 & 78.24 & 73.94 & 100 & 90.65 & 73.82 & 70.42 & 45.27 \\
\hline 2 & 88.65 & 81.47 & 100 & 97.34 & 81.46 & 83.29 & 50.94 \\
\hline 1 & 94.27 & 89.53 & 100 & 100 & 88.73 & 89.64 & 62.35 \\
\hline 0 & 100 & 100 & 100 & 100 & 100 & 100 & 100 \\
\hline
\end{tabular}

Table 3 Cytotoxicity of compounds 15, 16, 17, 18, 19, 20 and Doxorubicin against hepatocellular carcinoma cell line HePG2

\begin{tabular}{llllllll}
\hline Concentration $\boldsymbol{\mu g} / \mathbf{m L}$ & \multicolumn{2}{l}{ Viability $(\%) /$ compound } & & & \\
\cline { 2 - 7 } & $\mathbf{1 5}$ & $\mathbf{1 6}$ & $\mathbf{1 7}$ & $\mathbf{1 8}$ & $\mathbf{1 9}$ & $\mathbf{2 0}$ & Doxorubicin \\
\hline $\mathbf{5 0 0}$ & 6.49 & 4.31 & 6.78 & 4.68 & 3.84 & 6.91 & 3.6 \\
$\mathbf{2 5 0}$ & 11.25 & 11.72 & 15.93 & 10.35 & 9.65 & 11.76 & 3.97 \\
$\mathbf{1 2 5}$ & 19.43 & 18.25 & 24.85 & 17.46 & 13.81 & 20.95 & 6.43 \\
$\mathbf{6 2 . 5}$ & 30.61 & 23.87 & 34.91 & 25.72 & 19.46 & 32.47 & 9.68 \\
$\mathbf{3 1 . 2 5}$ & 39.45 & 30.64 & 42.87 & 32.69 & 25.83 & 44.35 & 16.45 \\
$\mathbf{1 5 . 6}$ & 51.26 & 38.92 & 67.29 & 44.82 & 32.17 & 76.97 & 23.87 \\
$\mathbf{7 . 8}$ & 67.18 & 47.30 & 83.97 & 51.96 & 39.68 & 89.50 & 30.69 \\
$\mathbf{3 . 9}$ & 84.91 & 64.59 & 91.48 & 64.53 & 48.54 & 94.16 & 37.54 \\
$\mathbf{2}$ & 92.73 & 76.28 & 98.02 & 72.31 & 61.83 & 98.73 & 42.91 \\
$\mathbf{1}$ & 96.48 & 81.49 & 100 & 79.48 & 69.42 & 100 & 48.76 \\
$\mathbf{0}$ & 100 & 100 & 100 & 100 & 100 & 100 & 100 \\
\hline
\end{tabular}

Table 4 Cytotoxicity of compounds 1, 2, 3, 4, 5, 6, 7 and 8 against breast carcinoma cell line MCF-7

\begin{tabular}{|c|c|c|c|c|c|c|c|c|}
\hline \multirow[t]{2}{*}{ Concentration $\mu \mathrm{g} / \mathrm{mL}$} & \multicolumn{8}{|c|}{ Viability (\%)/compound } \\
\hline & 1 & 2 & 3 & 4 & 5 & 6 & 7 & 8 \\
\hline 500 & 7.18 & 22.34 & 3.86 & 9.26 & 4.23 & 37.15 & 16.27 & 8.07 \\
\hline 250 & 13.95 & 34.51 & 9.62 & 20.84 & 9.06 & 51.49 & 29.38 & 16.56 \\
\hline 125 & 24.82 & 45.28 & 14.87 & 28.63 & 15.38 & 74.01 & 38.69 & 24.56 \\
\hline 62.5 & 32.93 & 73.69 & 20.65 & 36.59 & 21.75 & 88.63 & 49.16 & 31.88 \\
\hline 31.25 & 45.06 & 86.13 & 26.83 & 42.67 & 28.91 & 97.89 & 71.32 & 40.31 \\
\hline 15.6 & 60.83 & 94.56 & 36.54 & 48.54 & 36.42 & 100 & 86.04 & 52.76 \\
\hline 7.8 & 79.62 & 98.94 & 45.02 & 65.18 & 42.37 & 100 & 93.76 & 68.49 \\
\hline 3.9 & 85.21 & 100 & 60.89 & 80.95 & 50.16 & 100 & 98.51 & 82.53 \\
\hline 2 & 92.37 & 100 & 78.15 & 91.79 & 65.24 & 100 & 100 & 91.42 \\
\hline 1 & 98.64 & 100 & 86.41 & 95.48 & 76.35 & 100 & 100 & 97.17 \\
\hline 0 & 100 & 100 & 100 & 100 & 100 & 100 & 100 & 100 \\
\hline
\end{tabular}


Table 5 Cytotoxicity of compounds 9, 10, 11a, 11b, 12, 13, 14 and 15 against breast carcinoma cell line MCF-7

\begin{tabular}{|c|c|c|c|c|c|c|c|}
\hline \multirow[t]{2}{*}{ Concentration $\mu \mathrm{g} / \mathrm{mL}$} & \multicolumn{7}{|c|}{ Viability (\%)/compound } \\
\hline & 9 & 10 & $11 a$ & $11 \mathrm{~b}$ & 12 & 13 & 14 \\
\hline 500 & 8.09 & 6.48 & 31.79 & 8.51 & 6.37 & 5.96 & 5.08 \\
\hline 250 & 17.24 & 15.72 & 49.81 & 20.38 & 14.75 & 11.74 & 10.24 \\
\hline 125 & 26.85 & 24.16 & 78.26 & 32.75 & 23.81 & 20.82 & 18.76 \\
\hline 62.5 & 37.51 & 35.29 & 89.47 & 45.06 & 34.93 & 27.41 & 24.95 \\
\hline 31.25 & 45.97 & 42.81 & 95.24 & 61.78 & 40.84 & 34.92 & 30.88 \\
\hline 15.6 & 57.20 & 51.56 & 99.71 & 79.39 & 49.60 & 44.73 & 36.78 \\
\hline 7.8 & 74.19 & 69.37 & 100 & 92.64 & 70.38 & 65.46 & 42.97 \\
\hline 3.9 & 88.43 & 86.02 & 100 & 98.25 & 81.49 & 79.25 & 51.36 \\
\hline 2 & 95.72 & 93.88 & 100 & 100 & 92.63 & 90.48 & 59.28 \\
\hline 1 & 99.34 & 97.40 & 100 & 100 & 96.75 & 96.23 & 72.83 \\
\hline 0 & 100 & 100 & 100 & 100 & 100 & 100 & 100 \\
\hline
\end{tabular}

Table 6 Cytotoxicity of compounds 15, 16, 17, 18, 19, 20 and Doxorubicin against breast carcinoma cell line MCF-7

\begin{tabular}{llllllll}
\hline Concentration $\boldsymbol{\mu g} / \mathbf{m L}$ & \multicolumn{2}{l}{ Viability (\%)/compound } \\
\cline { 2 - 8 } & $\mathbf{1 5}$ & $\mathbf{1 6}$ & $\mathbf{1 7}$ & $\mathbf{1 8}$ & $\mathbf{1 9}$ & $\mathbf{2 0}$ & Doxorubicin \\
\hline $\mathbf{5 0 0}$ & 8.76 & 5.28 & 7.95 & 6.17 & 5.21 & 8.25 & 1.51 \\
$\mathbf{2 5 0}$ & 13.81 & 13.96 & 21.34 & 13.92 & 11.36 & 16.37 & 2.36 \\
$\mathbf{1 2 5}$ & 26.92 & 21.47 & 30.67 & 21.40 & 20.84 & 28.72 & 3.21 \\
$\mathbf{6 2 . 5}$ & 37.24 & 32.68 & 38.72 & 28.57 & 27.30 & 41.89 & 5.07 \\
$\mathbf{3 1 . 2 5}$ & 48.17 & 36.43 & 51.90 & 36.71 & 35.26 & 49.78 & 6.93 \\
$\mathbf{1 5 . 6}$ & 60.95 & 42.90 & 64.18 & 48.86 & 39.48 & 80.93 & 15.46 \\
$\mathbf{7 . 8}$ & 76.43 & 51.72 & 72.37 & 69.52 & 46.29 & 92.34 & 19.89 \\
$\mathbf{3 . 9}$ & 89.71 & 69.37 & 88.45 & 81.94 & 54.68 & 97.28 & 24.98 \\
$\mathbf{2}$ & 97.02 & 83.19 & 92.32 & 90.68 & 69.31 & 100 & 31.69 \\
$\mathbf{1}$ & 100 & 92.48 & 97.45 & 96.25 & 80.47 & 100 & 40.17 \\
$\mathbf{0}$ & 100 & 100 & 100 & 100 & 100 & 100 & 100 \\
\hline
\end{tabular}

(E)-1-(2-\{3-[1-(4-bromophenyl)ethylideneamino]-4-oxo-2thioxoimidazolidin-1-yl\}acetyl)-3-methyl-1H-pyrazol5(4H)-one 5 Yellow crystals, in yield 74\%, m.p 177$179{ }^{\circ} \mathrm{C} .{ }^{1} \mathrm{H}-\mathrm{NMR}\left(\mathrm{DMSO}-d_{6}\right): \delta=7.74(\mathrm{~d}, 2 \mathrm{H}, J=8.5 \mathrm{~Hz}$, $2 \mathrm{CH}), 7.65(\mathrm{~d}, 2 \mathrm{H}, J=8.5 \mathrm{~Hz}, 2 \mathrm{CH}), 4.52\left(\mathrm{~s}, 2 \mathrm{H}, \mathrm{CH}_{2}\right)$, 4.09 (s, 2H, $\left.\mathrm{CH}_{2}\right), 3.89\left(\mathrm{~s}, 2 \mathrm{H}, \mathrm{CH}_{2}\right), 2.34\left(\mathrm{~s}, 3 \mathrm{H}, \mathrm{CH}_{3}\right)$ and $1.89\left(\mathrm{~s}, 3 \mathrm{H}, \mathrm{CH}_{3}\right) \mathrm{ppm} .{ }^{13} \mathrm{C}-\mathrm{NMR}\left(\mathrm{DMSO}-d_{6}\right): \delta=171.73$ $(\mathrm{C}=\mathrm{S}), 168.02,167.01,164.60(3 \mathrm{C}=\mathrm{O}), 161.47,161.29$ $(\mathrm{C}=\mathrm{N}), 136.68,131.43,128.53,123.71$ (C-aromatic), 61.33, 43.80, $32.16\left(3 \mathrm{CH}_{2}\right)$ and $20.47,14.62\left(2 \mathrm{CH}_{3}\right)$. IR (KBr): 1716, $1741(\mathrm{C}=\mathrm{O}), 1605,1589(2 \mathrm{C}=\mathrm{N})$ and $1386(\mathrm{C}=\mathrm{S}) \mathrm{cm}^{-1}$. MS: $\mathrm{m} / \mathrm{z}$ (\%): 450 (13), $449\left(\mathrm{M}^{+}\right.$, $\left.{ }^{79} \mathrm{Br}, 23\right), 451\left(\mathrm{M}^{+},{ }^{81} \mathrm{Br}, 7\right)$ and 427 (100). Anal. Calcd. $\mathrm{C}_{17} \mathrm{H}_{16} \mathrm{BrN}_{5} \mathrm{O}_{3} \mathrm{~S}$ (450.31): C, 45.34; H, 3.58; Br, 17.74; N, 15.55; S, 7.12;. Found. C, 45.38; H, 3.62; Br, 17.83; N, $15.49 ; \mathrm{S}, 7.15$.
(E)-3-[1-(4-bromophenyl)ethylideneamino]-1-\{2-(3,5dimethyl-1H-pyrazol-1-yl)-2-oxoethyl $\}$-2-thioxoimidazolidin-4-one 6 Black crystals, in yield 82\%, m.p 83-85 ${ }^{\circ} \mathrm{C}$. ${ }^{1} \mathrm{H}-\mathrm{NMR} \quad\left(\mathrm{DMSO}-d_{6}\right): \delta=7.89-7.65(\mathrm{~m}, 5 \mathrm{H}, \mathrm{Ar}-\mathrm{H})$, $4.52\left(\mathrm{~s}, 2 \mathrm{H}, \mathrm{CH}_{2}\right), 4.10\left(\mathrm{~s}, 2 \mathrm{H}, \mathrm{CH}_{2}\right), 2.57\left(\mathrm{~s}, 3 \mathrm{H}, \mathrm{CH}_{3}\right)$, $2.34\left(\mathrm{~s}, 3 \mathrm{H}, \mathrm{CH}_{3}\right)$ and $1.82\left(\mathrm{~s}, 3 \mathrm{H}, \mathrm{CH}_{3}\right) \mathrm{ppm} .{ }^{13} \mathrm{C}-\mathrm{NMR}$ $\left(\mathrm{DMSO}-d_{6}\right): \delta=170.05(\mathrm{C}=\mathrm{S}), 166.18,164.60(2 \mathrm{C}=\mathrm{O})$, $160.36,160.19(2 \mathrm{C}=\mathrm{N}), 138.16,138.08,132.57,132.14$, $128.20,123.43$ (C-aromatic) and $58.75,31.19\left(2 \mathrm{CH}_{2}\right)$, 19.83, 16.34, $14.52\left(3 \mathrm{CH}_{3}\right)$ ppm. IR (KBr): $1722(\mathrm{C}=\mathrm{O})$, 1607, $1585(2 \mathrm{C}=\mathrm{N})$ and $1370(\mathrm{C}=\mathrm{S}) \mathrm{cm}^{-1}$. MS: $\mathrm{m} / \mathrm{z}(\%)$ : 448 (12), $447\left(\mathrm{M}^{+},{ }^{79} \mathrm{Br}, 5\right)$ and $450\left({ }^{81} \mathrm{Br}, \mathrm{M}^{+}+1,14\right), 76$ (100). Anal. Calcd. $\mathrm{C}_{18} \mathrm{H}_{18} \mathrm{BrN}_{5} \mathrm{O}_{2} \mathrm{~S}$ (448.34): C, 48.22; $\mathrm{H}$, 4.05; Br, 17.82; N, 15.62; S, 7.15. Found. C, 48.31; H, 3.95; Br, 17.95; N, 15.70; S, 7.21. 
Table $7 \mathrm{IC}_{50}$ of the tested compounds against hepatocellular carcinoma cell line HePG2 and breast cancer cell line MCF-7

\begin{tabular}{lll}
\hline Compound no. & HepG-2 cell line & MCF-7 cell line \\
\hline $\mathbf{1}$ & 14.7 & 26.3 \\
$\mathbf{2}$ & 102 & 115 \\
$\mathbf{3}$ & 4.54 & 6.58 \\
$\mathbf{4}$ & 15.4 & 14.9 \\
$\mathbf{5}$ & 3.42 & 3.98 \\
$\mathbf{6}$ & 229 & 276 \\
$\mathbf{7}$ & 51.5 & 61.3 \\
$\mathbf{8}$ & 14.1 & 19.1 \\
$\mathbf{9}$ & 14.9 & 25.6 \\
$\mathbf{1 0}$ & 13.5 & 18.4 \\
$\mathbf{1 1 a}$ & 243 & 249 \\
$\mathbf{1 1 b}$ & 32.2 & 53.3 \\
$\mathbf{1 2}$ & 10.9 & 15.4 \\
$\mathbf{1 3}$ & 12.9 & 13.6 \\
$\mathbf{1 4}$ & 2.33 & 4.53 \\
$\mathbf{1 5}$ & 17.3 & 29 \\
$\mathbf{1 6}$ & 7.19 & 9.32 \\
$\mathbf{1 7}$ & 26.6 & 35.8 \\
$\mathbf{1 8}$ & 9.94 & 15.2 \\
$\mathbf{1 9}$ & 3.78 & 6.08 \\
$\mathbf{2 0}$ & 28.5 & 31.1 \\
Doxorubicin & 0.85 & 0.35 \\
\hline
\end{tabular}

(E)-1-(2-\{3-[1-(4-bromophenyl)ethylideneamino]-4oxo-2-thioxoimidazolidin-1-yl\}acetyl)pyrazolidine-3,5-dione 7 Pale yellow crystals, in yield $69 \%$, m.p $228-230{ }^{\circ} \mathrm{C}$. ${ }^{1} \mathrm{H}-\mathrm{NMR}\left(\mathrm{DMSO}-d_{6}\right): \delta=10.81(\mathrm{~s}, 1 \mathrm{H}, \mathrm{NH}), 7.66(\mathrm{~d}, 2 \mathrm{H}$, $J=8.5 \mathrm{~Hz}, 2 \mathrm{CH}), 7.63(\mathrm{~d}, 2 \mathrm{H}, J=8.5 \mathrm{~Hz}, 2 \mathrm{CH}), 4.52(\mathrm{~s}$, $\left.2 \mathrm{H}, \mathrm{CH}_{2}\right), 4.10\left(\mathrm{~s}, 2 \mathrm{H}, \mathrm{CH}_{2}\right), 4.03\left(\mathrm{~s}, 2 \mathrm{H}, \mathrm{CH}_{2}\right)$ and $2.34(\mathrm{~s}$, $\left.3 \mathrm{H}, \mathrm{CH}_{3}\right)$ ppm. ${ }^{13} \mathrm{C}-\mathrm{NMR}\left(\mathrm{DMSO}-d_{6}\right): \delta=174.12(\mathrm{C}=\mathrm{S})$, $169.25,166.78,165.44,163.99(4 \mathrm{C}=\mathrm{O}), 159.89(\mathrm{C}=\mathrm{N})$, 132.41, 131.43, 128.45, 123.98 (C-aromatic), 58.55, 44.32, $31.73\left(3 \mathrm{CH}_{2}\right)$ and $16.67\left(\mathrm{CH}_{3}\right)$ ppm. IR $(\mathrm{KBr}): 3196(\mathrm{NH})$, $1717(\mathrm{C}=\mathrm{O}), 1603(\mathrm{C}=\mathrm{N})$ and $1392(\mathrm{C}=\mathrm{S}) \mathrm{cm}^{-1}$. MS: $\mathrm{m} / \mathrm{z}(\%): 453(6), 452\left(\mathrm{M}^{+},{ }^{79} \mathrm{Br}, 11\right)$ and $454\left(\mathrm{M}^{+},{ }^{81} \mathrm{Br}\right.$, 10) and 101 (100). Anal. Calcd. $\mathrm{C}_{16} \mathrm{H}_{14} \mathrm{BrN}_{5} \mathrm{O}_{4} \mathrm{~S}$ (452.28): C, 42.49; H, 3.12; Br, 17.67; N, 15.48; S, 7.09;. Found. C, 42.42; H, 3.15; Br, 17.60; N, 15.40; S, 7.11.

\section{Synthesis of (E)-5-amino-1-(2-\{3-[1-(4-bromophenyl) ethylideneamino]-4-oxo-2-thioxoimidazolidin-1-yl\} acetyl)-1 $\mathrm{H}$-pyrazole-4-carbonitrile 8}

To compound $4(0.01 \mathrm{~mol})$ dissolved in $50 \mathrm{~mL}$ absolute ethanol was added slowly with shaking, ethoxymethylenemalononitrile $(0.01 \mathrm{~mol})$, after addition of about half of the quantity, the solution was carefully heated to boiling. The remaining ethoxymethylenemalononitrile was added, at such a rate to maintain gentle boiling of the solution, after all the ethoxymethylenemalononitrile had been added, the solution was gently boiled for an additional $30 \mathrm{~min}$ and finally was set aside overnight in the refrigerator. The product formed was filtered off, dried and crystallized from ethanol to give $\mathbf{8}$ as yellow crystals, in yield $84 \%$, m.p $198-200{ }^{\circ} \mathrm{C} .{ }^{1} \mathrm{H}-\mathrm{NMR}$ (DMSO- $d_{6}$ ): $\delta=7.79-7.62(\mathrm{~m}, 5 \mathrm{H}, \mathrm{Ar}-\mathrm{H}, \mathrm{N}=\mathrm{CH}), 4.94\left(\mathrm{~s}, 2 \mathrm{H}, \mathrm{NH}_{2}\right)$, $4.68\left(\mathrm{~s}, 2 \mathrm{H}, \mathrm{CH}_{2}\right), 4.55\left(\mathrm{~s}, 2 \mathrm{H}, \mathrm{CH}_{2}\right)$ and $2.35\left(\mathrm{~s}, 3 \mathrm{H}, \mathrm{CH}_{3}\right)$ ppm. ${ }^{13} \mathrm{C}-\mathrm{NMR}$ (DMSO- $d_{6}$ ): $\delta=172.00(\mathrm{C}=\mathrm{S}), 165.21$, $162.77(2 \mathrm{C}=\mathrm{O}), 161.06,160.87(2 \mathrm{C}=\mathrm{N}), 119.51(\mathrm{CN})$, $136.79,131.46,131.39,128.45,128.26$ (C-aromatic), 43.87, $32.30\left(2 \mathrm{CH}_{2}\right)$ and $14.49\left(\mathrm{CH}_{3}\right)$ ppm. IR $(\mathrm{KBr}): 3289$, 3194 $\left(\mathrm{NH}_{2}\right), 2203(\mathrm{CN}), 1726,1660(\mathrm{C}=\mathrm{O}), 1606(\mathrm{C}=\mathrm{N})$ and $1388(\mathrm{C}=\mathrm{S}) \mathrm{cm}^{-1}$. MS: $\mathrm{m} / \mathrm{z}(\%): 460(5), 459\left(\mathrm{M}^{+}\right.$, $\left.{ }^{79} \mathrm{Br}, 11\right), 461\left(\mathrm{M}^{+},{ }^{81} \mathrm{Br}, 10\right)$ and 383 (100). Anal. Cald. $\mathrm{C}_{17} \mathrm{H}_{14} \mathrm{BrN}_{7} \mathrm{O}_{2} \mathrm{~S}$ (460.31): C, 44.36; H, 3.07; Br, 17.36; N, 21.30; S, 6.97. Found. C, 44.52; H, 3.13; Br, 17.48; N, 21.27; S, 6.83 .

\section{Synthesis of (E)-2-(2-\{3-[1-(4-bromophenyl) ethylideneamino]-4-oxo-2-thioxoimidazolidin-1-yl\} acetyl)- $\mathrm{N}$-phenylhydrazinecarbothioamide 9}

A mixture of $4(0.01 \mathrm{~mol})$ and phenyl isothiocyanate $(0.01 \mathrm{~mol})$ in dimethylformamide $(25 \mathrm{~mL})$ was stirred under reflux for $5 \mathrm{~h}$. The reaction mixture then cooled to room temperature, poured into ice water, then acidified with dilute hydrochloric acid. The resulting solid was filtered off, washed with water, dried and purified by crystallization from ethanol to give 9 as orange crystals, in yield $89 \%$, m.p $68-70{ }^{\circ} \mathrm{C}$. ${ }^{1} \mathrm{H}$-NMR (DMSO- $\left.d_{6}\right): \delta=11.06(\mathrm{~s}, 1 \mathrm{H}, \mathrm{NH}), 8.54(\mathrm{~s}, 1 \mathrm{H}$, $\mathrm{NH}), 9.86(\mathrm{~s}, 1 \mathrm{H}, \mathrm{NH}), 7.71-7.24(\mathrm{~m}, 9 \mathrm{H}, \mathrm{Ar}-\mathrm{H}), 4.52(\mathrm{~s}$, $\left.2 \mathrm{H}, \mathrm{CH}_{2}\right), 4.16\left(\mathrm{~s}, 2 \mathrm{H}, \mathrm{CH}_{2}\right)$ and $2.33\left(\mathrm{~s}, 3 \mathrm{H}, \mathrm{CH}_{3}\right) \mathrm{ppm}$. IR $(\mathrm{KBr}): 3189(\mathrm{NH}), 1653,1723(\mathrm{C}=\mathrm{O}), 1607(\mathrm{C}=\mathrm{N})$ and 1385 $(\mathrm{C}=\mathrm{S}) \mathrm{cm}^{-1}$. MS: $\mathrm{m} / \mathrm{z}(\%): 519$ (3), $518\left(\mathrm{M}^{+},{ }^{79} \mathrm{Br}, 6\right), 520$ $\left(\mathrm{M}^{+},{ }^{81} \mathrm{Br}, 5\right)$ and 438 (100). Anal. Calcd. $\mathrm{C}_{20} \mathrm{H}_{19} \mathrm{BrN}_{6} \mathrm{O}_{2} \mathrm{~S}_{2}$ (519.44): C, 46.24; H, 3.69; Br, 15.38; N, 16.18; S, 12.35 . Found. C, 46.19; H, 3.59; Br, 15.52; N, 16.25; S, 12.39 .

\section{Synthesis of (E)-3-[1-(4-bromophenyl) ethylideneamino]-1-\{(4-phenyl-5-thioxo-4,5-dihy- dro-1 $H$-1,2,4-triazol-3-yl)methyl\}-2-thioxoimidazoli- din-4-one 10}

A solution of $9(0.01 \mathrm{~mol})$ in ethanol $(30 \mathrm{~mL})$ was added with sodium hydroxide $(30 \mathrm{~mL} / 1 \mathrm{~N})$, then heated under reflux for $4 \mathrm{~h}$. The reaction mixture was cooled and acidified with diluted hydrochloric acid. The solid formed was filtered off, washed with water, dried and purified from ethanol to give $\mathbf{1 0}$ as white crystals, in yield $66 \%$, m.p $48-50{ }^{\circ} \mathrm{C}$. ${ }^{1} \mathrm{H}-\mathrm{NMR}$ (DMSO- $d_{6}$ ): $\delta=11.05$ (s, $1 \mathrm{H}, \mathrm{NH}), 7.79-7.35(\mathrm{~m}, 9 \mathrm{H}, \mathrm{Ar}-\mathrm{H}), 4.53\left(\mathrm{~s}, 2 \mathrm{H}, \mathrm{CH}_{2}\right)$, $4.04\left(\mathrm{~s}, 2 \mathrm{H}, \mathrm{CH}_{2}\right)$ and $2.26\left(\mathrm{~s}, 3 \mathrm{H}, \mathrm{CH}_{3}\right) \mathrm{ppm} .{ }^{13} \mathrm{C}-\mathrm{NMR}$ 
$\left(\mathrm{DMSO}-d_{6}\right): \delta=177.90,172.27(2 \mathrm{C}=\mathrm{S}), 166.25(\mathrm{C}=\mathrm{O})$, $159.16,159.02(2 \mathrm{C}=\mathrm{N}), 138.66,137.83,128.92,128.51$, 125.16, 124.70, 123.15, 121.76 (C-aromatic), 65.27, 30.77 $\left(2 \mathrm{CH}_{2}\right)$ and $14.03\left(\mathrm{CH}_{3}\right)$ ppm. IR $(\mathrm{KBr}): 3408(\mathrm{NH}), 1715$ $(\mathrm{C}=\mathrm{O}), 1604(\mathrm{C}=\mathrm{N})$ and $1385(\mathrm{C}=\mathrm{S}) \mathrm{cm}^{-1}$. MS: $\mathrm{m} / \mathrm{z}(\%)$ : 501 (6), $500\left(\mathrm{M}^{+},{ }^{79} \mathrm{Br}, 7\right), 502\left(\mathrm{M}^{+},{ }^{81} \mathrm{Br}, 3\right)$. Anal. Calcd. $\mathrm{C}_{20} \mathrm{H}_{17} \mathrm{BrN}_{6} \mathrm{OS}_{2}$ (501.42): C, 47.91; H, 3.42; Br, 15.94; N, 16.76; S, 12.79. Found. C, 47.83; H, 3.30, Br, 15.90; N, $16.81 ; \mathrm{S}, 12.83$.

\section{Syntheses of compounds $11 a$ and $11 b$}

A mixture of $4(0.01 \mathrm{~mol})$, aromatic aldehydes such as, (isonicotinaldehyde and anisaldehyde) $(0.01 \mathrm{~mol})$ and piperidine $(1 \mathrm{~mL})$ was fused on a hot plate at $100-110{ }^{\circ} \mathrm{C}$ for half an hour, then ethanol $(25 \mathrm{~mL})$ was added and refluxed for $2 \mathrm{~h}$. The reaction mixture then cooled and acidified with diluted hydrochloric acid. The resulting solid was filtered off, washed with water, dried and purified by crystallization from proper solvent to give 11a, $\mathbf{b}$.

(E)-2-\{3-[1-(4-Bromophenyl)ethylideneamino]-4-oxo-2-t hioxoimidazolidin-1-yl\}-N'-(pyridin-4-ylmethylene)acetohydrazide 11a Pale yellow crystals, in yield 84\%, m.p 270-272 ${ }^{\circ} \mathrm{C}$ (benzene). ${ }^{1} \mathrm{H}-\mathrm{NMR}$ (DMSO- $d_{6}$ ): $\delta=8.76-$ $7.64(\mathrm{~m}, 10 \mathrm{H}, \mathrm{Ar}-\mathrm{H}$, pyridine, $=\mathrm{CH}, \mathrm{NH}), 4.51(\mathrm{~s}, 2 \mathrm{H}$, $\left.\mathrm{CH}_{2}\right), 4.11\left(\mathrm{~s}, 2 \mathrm{H}, \mathrm{CH}_{2}\right)$ and $2.32\left(\mathrm{~s}, 3 \mathrm{H}, \mathrm{CH}_{3}\right) \mathrm{ppm}$. ${ }^{13} \mathrm{C}-\mathrm{NMR}\left(\mathrm{DMSO}-d_{6}\right): \delta=172.12(\mathrm{C}=\mathrm{S}), 167.32,163.44$ $(2 \mathrm{C}=\mathrm{O}), 162.72,142.32(2 \mathrm{C}=\mathrm{N}), 140.43,136.71,136.26$, 131.58, 128.83, 124.15, 123.59 (C-aromatic), 43.71, 32.12 $\left(\mathrm{CH}_{2}\right)$ and 14.38 $\left(\mathrm{CH}_{3}\right)$ ppm. IR $(\mathrm{KBr}): 3190(\mathrm{NH}), 1678$, 1724 $(\mathrm{C}=\mathrm{O}), 1607(\mathrm{C}=\mathrm{N})$ and $1396(\mathrm{C}=\mathrm{S}) \mathrm{cm}^{-1}$. MS: $\mathrm{m} / \mathrm{z}(\%): 473(28), 472\left(\mathrm{M}^{+},{ }^{79} \mathrm{Br}, 74\right)$ and $474\left(\mathrm{M}^{+},{ }^{81} \mathrm{Br}\right.$, 100). Anal. Calcd. $\mathrm{C}_{19} \mathrm{H}_{17} \mathrm{BrN}_{6} \mathrm{O}_{2} \mathrm{~S}$ (473.35): $\mathrm{C}$, 48.21; $\mathrm{H}$, 3.62; $\mathrm{Br}, 16.88 ; \mathrm{N}, 17.75 ; \mathrm{S}, 6.77$. Found. C, 48.29; H, 3.64; $\mathrm{Br}, 16.89 ; \mathrm{N}, 17.69 ; \mathrm{S}, 6.70$.

(E)-2-\{3-[1-(4-Bromophenyl)ethylideneamino]-4-oxo-2-t hioxoimidazolidin-1-yl\}-N'-(4-methoxybenzylidene)acetohydrazide 11b Pale yellow crystals, in yield 79\%, m.p 229-231 ${ }^{\circ} \mathrm{C}(\mathrm{EtOH}) .{ }^{1} \mathrm{H}-\mathrm{NMR}$ (DMSO- $\left.d_{6}\right): \delta=11.63(\mathrm{~s}$, $1 \mathrm{H}, \mathrm{NH}), 7.98-7.00(\mathrm{~m}, 9 \mathrm{H}, \mathrm{Ar}-\mathrm{H},=\mathrm{CH}), 4.46(\mathrm{~s}, 2 \mathrm{H}$, $\left.\mathrm{CH}_{2}\right), 4.08\left(\mathrm{~s}, 2 \mathrm{H}, \mathrm{CH}_{2}\right), 3.87\left(\mathrm{~s}, 3 \mathrm{H}, \mathrm{OCH}_{3}\right)$ and 2.33 $\left(\mathrm{s}, 3 \mathrm{H}, \mathrm{CH}_{3}\right.$ ) ppm. ${ }^{13} \mathrm{C}-\mathrm{NMR}$ (DMSO- $\left.d_{6}\right): \delta=172.73$ $(\mathrm{C}=\mathrm{S}), 167.10,162.54(2 \mathrm{C}=\mathrm{O}), 161.02,141.99(2 \mathrm{C}=\mathrm{N})$, $141.03,136.26,128.45,128.45,126.47,123.46,121.06$, 120.98 (C-aromatic), $56.77\left(\mathrm{OCH}_{3}\right), 44.49,32.23\left(2 \mathrm{CH}_{2}\right)$ and 14.44 $\left(\mathrm{CH}_{3}\right)$ ppm. IR (KBr): $3189(\mathrm{NH}), 1675,1723$ $(\mathrm{C}=\mathrm{O}), 1608(\mathrm{C}=\mathrm{N})$ and $1395(\mathrm{C}=\mathrm{S}) \mathrm{cm}^{-1}$. MS: $\mathrm{m} / \mathrm{z}$ (\%): 502 (38), $501\left(\mathrm{M}^{+},{ }^{79} \mathrm{Br}, 98\right)$ and $503\left(\mathrm{M}^{+},{ }^{81} \mathrm{Br}, 100\right)$. Anal. Calcd. $\mathrm{C}_{21} \mathrm{H}_{20} \mathrm{BrN}_{5} \mathrm{O}_{3} \mathrm{~S}$ (502.38): $\mathrm{C}$, 50.21; $\mathrm{H}, 4.01$; Br, 15.90; N, 13.94; S, 6.38,. Found. C, 50.10; H, 3.87: Br, $16.03 ; \mathrm{N}, 14.02$; S, 6.30 .

\section{Syntheses of compounds 12 and 13}

A mixture of $1(0.01 \mathrm{~mol})$ and triethyl orthoformate and/ or diethyl oxalate $(0.01 \mathrm{~mol})$ in xylene $(25 \mathrm{~mL})$ in the presence of sodium metal $(0.50 \mathrm{~g})$, was heated under reflux for $4 \mathrm{~h}$, then filtered upon hot and the filtrate then concentrated, cooled and the solid formed was filtered off, dried and purified by crystallization from ethanol to give 12 and 13 , respectively.

(E)-3-[1-(4-Bromophenyl)ethylideneamino]-5-(ethoxym ethylene)-2-thioxoimidazolidin-4-one 12 Brown crystals, in yield $73 \%$, m.p $181-183{ }^{\circ} \mathrm{C} .{ }^{1} \mathrm{H}-\mathrm{NMR}$ (DMSO$\left.d_{6}\right): \delta=11.42(\mathrm{~s}, 1 \mathrm{H}, \mathrm{NH}), 7.74(\mathrm{~d}, 2 \mathrm{H}, J=8.5 \mathrm{~Hz}, 2 \mathrm{CH})$, $7.66(\mathrm{~d}, 2 \mathrm{H}, J=8.5 \mathrm{~Hz}, 2 \mathrm{CH}), 7.08(\mathrm{~s}, 1 \mathrm{H},=\mathrm{CHO}), 4.15$ (q, $\left.2 \mathrm{H}, J=8.6 \mathrm{~Hz}, \mathrm{CH}_{2}\right), 2.29\left(\mathrm{~s}, 3 \mathrm{H}, \mathrm{CH}_{3}\right)$ and 1.05 $\left(\mathrm{t}, 3 \mathrm{H}, J=6.8 \mathrm{~Hz}, \mathrm{CH}_{3}\right.$ ) ppm. ${ }^{13} \mathrm{C}-\mathrm{NMR}$ (DMSO- $d_{6}$ ): $\delta=172.09(\mathrm{C}=\mathrm{S}), 164.58(\mathrm{C}=\mathrm{O}), 159.32(\mathrm{C}=\mathrm{N}), 135.92$ (CH), 133.99, 131.70, 128.24, 123.33 (C-aromatic), 115.45 $(\mathrm{HNC}=), 65.57\left(\mathrm{CH}_{2}\right)$ and 18.28, $14.32\left(2 \mathrm{CH}_{3}\right) \mathrm{ppm}$. IR $(\mathrm{KBr}): 3320(\mathrm{NH}), 1751(\mathrm{C}=\mathrm{O}), 1621(\mathrm{C}=\mathrm{N})$ and 1396 $(\mathrm{C}=\mathrm{S}) \mathrm{cm}^{-1}$. MS: $\mathrm{m} / \mathrm{z}(\%): 368$ (5), $367\left(\mathrm{M}^{+},{ }^{79} \mathrm{Br}, 4\right), 369$ $\left(\mathrm{M}^{+},{ }^{81} \mathrm{Br}, 3\right)$ and 57 (100). Anal. Calcd. $\mathrm{C}_{14} \mathrm{H}_{14} \mathrm{BrN}_{3} \mathrm{O}_{2} \mathrm{~S}$ (368.25): C, 45.66; H, 3.83; Br, 21.70; N, 11.41; S, 8.71. Found. C, 45.57; H, 3.72; Br, 21.68; N, 11.48; S, 8.58.

(E)-Ethyl 2-\{1-[1-(4-bromophenyl)ethylideneamino]-5-oxo2-thioxoimidazolidin-4-yl\}-2-oxoacetate 13 Yellow crystals, in yield $75 \%$, m.p $161-163^{\circ} \mathrm{C} .{ }^{1} \mathrm{H}-\mathrm{NMR}$ (DMSO$\left.d_{6}\right): \delta=12.00(\mathrm{~s}, 1 \mathrm{H}, \mathrm{NH}), 7.74(\mathrm{~d}, 2 \mathrm{H}, J=8.5 \mathrm{~Hz}, 2 \mathrm{CH})$, $7.66(\mathrm{~d}, 2 \mathrm{H}, J=8.5 \mathrm{~Hz}, 2 \mathrm{CH}), 4.43(\mathrm{~s}, 1 \mathrm{H}, \mathrm{CH}), 4.20(\mathrm{q}$, $\left.2 \mathrm{H}, J=4.2 \mathrm{~Hz}, \mathrm{CH}_{2}\right), 2.26\left(\mathrm{~s}, 3 \mathrm{H}, \mathrm{CH}_{3}\right)$ and $1.09(\mathrm{t}, 3 \mathrm{H}$, $\left.J=4.2 \mathrm{~Hz}, \mathrm{CH}_{3}\right)$ ppm. ${ }^{13} \mathrm{C}$-NMR (DMSO- $\left.d_{6}\right): \delta=176.02$ $(\mathrm{C}=\mathrm{S}), 166.82,163.64,163.11(\mathrm{C}=\mathrm{O}), 160.13(\mathrm{C}=\mathrm{N})$, 133.89, 131.40, 128.70, 123.38 (C-aromatic), $72.31(\mathrm{CH})$, $56.03\left(\mathrm{CH}_{2}\right)$ and 14.44, $13.79\left(2 \mathrm{CH}_{3}\right)$ ppm. IR $(\mathrm{KBr})$ : $3411(\mathrm{NH}), 1716(\mathrm{C}=\mathrm{O}), 1762(\mathrm{C}=\mathrm{O}$ ester $), 1606(\mathrm{C}=\mathrm{N})$ and $1389(\mathrm{C}=\mathrm{S}) \mathrm{cm}^{-1}$. MS: $\mathrm{m} / \mathrm{z}(\%): 412(6), 411\left(\mathrm{M}^{+}\right.$, $\left.{ }^{79} \mathrm{Br}, 8\right), 413\left(\mathrm{M}^{+},{ }^{81} \mathrm{Br}, 13\right)$ and 75 (100). Anal. Calcd. $\mathrm{C}_{15} \mathrm{H}_{14} \mathrm{BrN}_{3} \mathrm{O}_{4} \mathrm{~S}$ (412.26): C, 43.70; $\mathrm{H}, 3.42 ; \mathrm{Br}, 19.38$; N, 10.19; S, 7.78. Found. C, 43.58; H, 3.47; Br, 19.51; N, $10.05 ;$ S, 7.65 .

\section{Syntheses of compounds 14 and 15}

A mixture of $\mathbf{1 3}(0.01 \mathrm{~mol})$ and $o$-phenylenediamine or 2-aminophenol $(0.01 \mathrm{~mol})$ in acetic acid $(25 \mathrm{~mL})$ was fused under reflux for $2-3 \mathrm{~h}$, then cooled. The solid formed was filtered off, washed with ethanol, dried and purified by crystallization from ethanol to give $\mathbf{1 4}$ and $\mathbf{1 5}$.

(E)-5-(1H-benzo[d]imidazole-2-carbonyl)-3-[1-(4-bromophenyl)ethylideneamino]-2-thioxoimidazolidin-4-one 14 Brown crystals, in yield 63\%, m.p $238-240{ }^{\circ} \mathrm{C}$. 
${ }^{1} \mathrm{H}-\mathrm{NMR}$ (DMSO- $d_{6}$ ): $\delta=11.99(\mathrm{~s}, 1 \mathrm{H}, \mathrm{NH}), 10.26(\mathrm{~s}$, $1 \mathrm{H}, \mathrm{NH}), 7.91-7.55(\mathrm{~m}, 8 \mathrm{H}, \mathrm{Ar}-\mathrm{H}), 4.30(\mathrm{~s}, 1 \mathrm{H}, \mathrm{CH})$ and $2.28\left(\mathrm{~s}, 3 \mathrm{H}, \mathrm{CH}_{3}\right)$ ppm. ${ }^{13} \mathrm{C}-\mathrm{NMR}$ (DMSO- $\left.d_{6}\right): \delta=178.97$ $(\mathrm{C}=\mathrm{S}), 169.08,167.10(2 \mathrm{C}=\mathrm{O}), 160.27,146.63(2 \mathrm{C}=\mathrm{N})$, 136.89, 135.80, 131.56, 130.22, 128.41, 127.30, 123.38, 122.90 (C-aromatic), $73.3(\mathrm{CH})$ and $14.47\left(\mathrm{CH}_{3}\right) \mathrm{ppm}$. IR (KBr): 3385, $3305(2 \mathrm{NH}), 1704,1730(2 \mathrm{C}=\mathrm{O}), 1615$ $(\mathrm{C}=\mathrm{N})$ and $1393(\mathrm{C}=\mathrm{S}) \mathrm{cm}^{-1}$. MS: $\mathrm{m} / \mathrm{z}(\%): 456(4), 455$ $\left(\mathrm{M}^{+},{ }^{79} \mathrm{Br}, 6\right), 457\left(\mathrm{M}^{+},{ }^{81} \mathrm{Br}, 3\right)$ and 339 (100). Anal. Calcd. $\mathrm{C}_{19} \mathrm{H}_{14} \mathrm{BrN}_{5} \mathrm{O}_{2} \mathrm{~S}$ (456.32): C, 50.01; H, 3.09; Br, 17.51; N, 15.35; S, 7.03. Found C, 49.91; H, 2.93; Br, 17.49; N, 15.42; S, 7.11 .

(E)-5-(Benzo[d]oxazole-2-carbonyl)-3-[1-(4-bromophenyl) ethylideneamino]-2-thioxoimidazolidin-4-one 15 Pale orange crystals, in yield $65 \%$, m.p $103-105{ }^{\circ} \mathrm{C} .{ }^{1} \mathrm{H}-\mathrm{NMR}$ (DMSO- $\left.d_{6}\right): \delta=9.87(\mathrm{~s}, 1 \mathrm{H}, \mathrm{NH}), 7.89-7.20(\mathrm{~m}, 8 \mathrm{H}$, $\mathrm{Ar}-\mathrm{H}), 4.30(\mathrm{~s}, 1 \mathrm{H}, \mathrm{CH})$ and $2.31\left(\mathrm{~s}, 3 \mathrm{H}, \mathrm{CH}_{3}\right) \mathrm{ppm}$. IR $(\mathrm{KBr}): 3198(\mathrm{NH}), 1661,1705(2 \mathrm{C}=\mathrm{O}), 1616(\mathrm{C}=\mathrm{N})$ and $1394(\mathrm{C}=\mathrm{S}) \mathrm{cm}^{-1}$. MS: $\mathrm{m} / \mathrm{z}(\%): 457(48), 456\left(\mathrm{M}^{+}\right.$, $\left.{ }^{79} \mathrm{Br}, 39\right), 458\left(\mathrm{M}^{+},{ }^{81} \mathrm{Br}, 75\right)$ and 443 (100). Anal. Calcd. $\mathrm{C}_{19} \mathrm{H}_{13} \mathrm{BrN}_{4} \mathrm{O}_{3} \mathrm{~S}$ (457.30): C, 49.90; H, 2.87; Br, 17.47; N, 12.25; S, 7.01. Found. C, 49.81; H, 2.75; Br, 17.62; N, 12.32; S, 6.91 .

\section{Synthesis of (E)-1-acetyl-3-[1-(4-bromophenyl)} ethylideneamino]-2-thioxoimidazolidin-4-one 16

A solution of $1(0.01 \mathrm{~mol})$ in acetic anhydride $(25 \mathrm{~mL})$ was heated under reflux for $2 \mathrm{~h}$, then cooled and the resulting solid was collected by filtration, dried and purified by crystallization from benzene to give compound $\mathbf{1 6}$, as white crystals, in yield $88 \%$, m.p $164-166{ }^{\circ} \mathrm{C} .{ }^{1} \mathrm{H}-\mathrm{NMR}$ $\left(\right.$ DMSO- $\left.d_{6}\right): \delta=7.59(\mathrm{~d}, 2 \mathrm{H}, J=8.5 \mathrm{~Hz}, 2 \mathrm{CH}), 7.43(\mathrm{~d}, 2 \mathrm{H}$, $J=8.5 \mathrm{~Hz}, 2 \mathrm{CH}), 4.34\left(\mathrm{~s}, 2 \mathrm{H}, \mathrm{CH}_{2}\right), 2.23\left(\mathrm{~s}, 3 \mathrm{H}, \mathrm{CH}_{3}\right)$ and $2.07\left(\mathrm{~s}, 3 \mathrm{H}, \mathrm{CH}_{3}\right) \mathrm{ppm} .{ }^{13} \mathrm{C}-\mathrm{NMR}\left(\mathrm{DMSO}-d_{6}\right): \delta=172.13$ $(\mathrm{C}=\mathrm{S}), 164.75,163.69(2 \mathrm{C}=\mathrm{O}), 159.83(\mathrm{C}=\mathrm{N}), 137.28$, 131.36, 128.42, 122.26 (C-aromatic), $82.16\left(\mathrm{CH}_{2}\right), 22.16$ $\left(\mathrm{CH}_{3}\right)$ and $19.47\left(\mathrm{CH}_{3}\right)$ ppm. IR $(\mathrm{KBr}): 1647,1716 \mathrm{~cm}^{-1}$ $(2 \mathrm{C}=\mathrm{O}), 1600(\mathrm{C}=\mathrm{N})$ and $1395(\mathrm{C}=\mathrm{S}) \mathrm{cm}^{-1}$. MS: $\mathrm{m} / \mathrm{z}$ (\%): $354(22), 353\left(\mathrm{M}^{+},{ }^{79} \mathrm{Br}, 91\right)$ and $355\left(\mathrm{M}^{+},{ }^{81} \mathrm{Br}, 100\right)$. Anal. Calcd. $\mathrm{C}_{13} \mathrm{H}_{12} \mathrm{BrN}_{3} \mathrm{O}_{2} \mathrm{~S}$ (354.22): C, 44.08; H, 3.41; $\mathrm{Br}$, 22.56; N, 11.86; S, 9.05;. Found. C, 43.92; H, 3.45; Br, 22.64; N, 11.93; S, 9.13.

\section{Synthesis of (E)-1,5-diacetyl-3-[1-(4-bromophenyl) ethylideneamino]-2-thioxoimidazolidin-4-one 17}

A mixture of $1(0.01 \mathrm{~mol})$ and fused sodium acetate $(0.02 \mathrm{~mol})$ in acetic anhydride $(25 \mathrm{~mL})$ was heated under reflux for $3 \mathrm{~h}$, then cooled and poured into ice-water. The resulting solid was filtered off, washed with water, dried and purified by crystallization from benzene to give $\mathbf{1 7}$ as pale yellow crystals, in yield $62 \%$, m.p $183-185{ }^{\circ} \mathrm{C}$.
${ }^{1} \mathrm{H}-\mathrm{NMR}$ (DMSO- $d_{6}$ ): $\delta=7.54(\mathrm{~d}, 2 \mathrm{H}, J=8.5 \mathrm{~Hz}, 2 \mathrm{CH}$ ), $7.43(\mathrm{~d}, 2 \mathrm{H}, J=8.5 \mathrm{~Hz}, 2 \mathrm{CH}), 5.08(\mathrm{~s}, 1 \mathrm{H}, \mathrm{CH}), 2.25$ (s, $\left.3 \mathrm{H}, \mathrm{CH}_{3}\right), 2.23\left(\mathrm{~s}, 3 \mathrm{H}, \mathrm{CH}_{3}\right), 2.18\left(\mathrm{~s}, 3 \mathrm{H}, \mathrm{CH}_{3}\right) \mathrm{ppm} .{ }^{13} \mathrm{C}-$ NMR (DMSO- $\left.d_{6}\right): \delta=169.56(\mathrm{C}=\mathrm{S}), 167.85,164.89$, $163.14(3 \mathrm{C}=\mathrm{O}), 159.85(\mathrm{C}=\mathrm{N}), 137.56,131.42,128$, 28, 122.36 (C-aromatic), $78.00(\mathrm{CH}), 22.48,22.20$ and $18.58\left(3 \mathrm{CH}_{3}\right)$. IR $(\mathrm{KBr}): 1646,1723$ and $1752(3 \mathrm{C}=\mathrm{O})$, $1601(\mathrm{C}=\mathrm{N})$ and $1397(\mathrm{C}=\mathrm{S}) \mathrm{cm}^{-1}$. MS: $\mathrm{m} / \mathrm{z}(\%): 396$ (4), $395\left(\mathrm{M}^{+},{ }^{79} \mathrm{Br}, 18\right), 397\left(\mathrm{M}^{+},{ }^{81} \mathrm{Br}, 16\right)$ and $313(100)$. Anal. Calcd. $\mathrm{C}_{15} \mathrm{H}_{14} \mathrm{BrN}_{3} \mathrm{O}_{3} \mathrm{~S}$ (396.26): C, 45.47; H, 3.56; Br, 20.16; N, 10.60; S, 8.09. Found. C, 45.38; H, 3.59; Br, 20.12; N, 10.70; S, 7.98.

\section{Synthesis of (Z)-1-acetyl-3-[(E)-1-(4-bromophenyl)ethy lideneamino]-5-(4-hydroxy-3-methoxybenzylidene)-2 -thioxoimidazolidin-4-one 18}

A mixture of $16(0.01 \mathrm{~mol})$, vanillin $(0.01 \mathrm{~mol})$ and piperidine $(1 \mathrm{~mL})$ was fused on a hot plate at $100-110{ }^{\circ} \mathrm{C}$ for half an hour, then ethanol $(25 \mathrm{~mL})$ was added and refluxed for $2 \mathrm{~h}$. The reaction mixture then cooled and acidified with diluted hydrochloric acid. The resulting solid was filtered off, washed with water, dried and purified by crystallization from EtOH to give $\mathbf{1 8}$ as yellow crystals, in yield 73\%, m.p 78-80 ${ }^{\circ} \mathrm{C} .{ }^{1} \mathrm{H}-\mathrm{NMR}$ (DMSO$\left.d_{6}\right): \delta=10.26$ (br.s, $\left.1 \mathrm{H}, \mathrm{OH}\right), 7.61-6.95(\mathrm{~m}, 8 \mathrm{H}, \mathrm{Ar}-\mathrm{H}$, $\mathrm{CH}$ olefinic), $3.82\left(\mathrm{~s}, 3 \mathrm{H}, \mathrm{OCH}_{3}\right), 2.32\left(\mathrm{~s}, 3 \mathrm{H}, \mathrm{CH}_{3}\right)$ and $2.03\left(\mathrm{~s}, 3 \mathrm{H}, \mathrm{CH}_{3}\right) \mathrm{ppm}$. IR (KBr): 3395-3340 (OH), 1751, $1706(2 \mathrm{C}=\mathrm{O})$ groups, $1616(\mathrm{C}=\mathrm{N})$ and $1396(\mathrm{C}=\mathrm{S}) \mathrm{cm}^{-1}$. MS: $\mathrm{m} / \mathrm{z}$ (\%): 488 (11), $487\left(\mathrm{M}^{+},{ }^{79} \mathrm{Br}, 41\right), 489\left(\mathrm{M}^{+},{ }^{81} \mathrm{Br}\right.$, $39)$ and 430 (100). Anal. Calcd. $\mathrm{C}_{21} \mathrm{H}_{18} \mathrm{BrN}_{3} \mathrm{O}_{4} \mathrm{~S}$ (488.35): C, 51.65, H, 3.72; Br, 16.36; N, 8.60; S, 6.57. Found. C, $51.73 ; \mathrm{H}, 3.73 ; \mathrm{Br}, 16.28 ; \mathrm{N}, 8.55 ; \mathrm{S}, 6.50$.

Synthesis of (E)-3-[1-(4-bromophenyl)ethylideneamino]-1-[ (diethylamino)methyl]-2-thioxoimidazolidin-4-one 19

To a solution of $1(0.01 \mathrm{~mol})$ soluble in $50 \mathrm{~mL}$ ethanol was added, a mixture of secondary amines $(0.01 \mathrm{~mol})$ (diethylamine) and aqueous formaldehyde $37 \%(1.25 \mathrm{~mL})$ dissolved in $10 \mathrm{~mL}$ ethanol, drop wise throw $30 \mathrm{~min}$, then stirred at room temperature for $3 \mathrm{~h}$. Finally refrigerated for $48 \mathrm{~h}$ to form crystals. The solid formed was filtered off and crystallized from ethanol to give compound 19 as pale yellow crystals, in yield $70 \%$, m.p $122-124{ }^{\circ} \mathrm{C}$. ${ }^{1} \mathrm{H}-\mathrm{NMR}\left(\mathrm{DMSO}-d_{6}\right): \delta=7.75(\mathrm{~d}, 2 \mathrm{H}, J=8.5 \mathrm{~Hz}, 2 \mathrm{CH}$ ), $7.71(\mathrm{~d}, 2 \mathrm{H}, J=8.5 \mathrm{~Hz}, 2 \mathrm{CH}), 4.55\left(\mathrm{~s}, 2 \mathrm{H}, \mathrm{CH}_{2}\right), 3.89$ (s, $\left.2 \mathrm{H}, \mathrm{CH}_{2}\right), 2.80\left(\mathrm{q}, 4 \mathrm{H}, J=6.8 \mathrm{~Hz}, 2 \mathrm{CH}_{2}\right), 2.29(\mathrm{~s}, 3 \mathrm{H}$, $\left.\mathrm{CH}_{3}\right)$ and $1.08\left(\mathrm{t}, 6 \mathrm{H}, J=6.8 \mathrm{~Hz}, 2 \mathrm{CH}_{3}\right)$ ppm. IR $(\mathrm{KBr})$ : 2820, 2854 (C-aliphatic), 2970 (C-aromatic), $1720(\mathrm{C}=\mathrm{S})$, $1612(\mathrm{C}=\mathrm{N})$ and $1384(\mathrm{C}=\mathrm{S}) \mathrm{cm}^{-1}$. MS: $\mathrm{m} / \mathrm{z}(\%): 397$ (10), $396\left(\mathrm{M}^{+},{ }^{79} \mathrm{Br}, 15\right), 398\left(\mathrm{M}^{+},{ }^{81} \mathrm{Br}, 7\right)$ and 298 (100). Anal. Calcd. $\mathrm{C}_{16} \mathrm{H}_{21} \mathrm{BrN}_{4} \mathrm{OS}$ (397.33): C, 48.37; H, 5.33; $\mathrm{Br}, 20.11 ; \mathrm{N}, 14.10 ; \mathrm{S}, 8.07$. Found. C, 48.30; H, 5.38; Br, 20.23; N, 13.98; S, 8.14. 


\section{Synthesis of (1E,2E)-1,2-bis[1-(4-bromophenyl)ethylidene]} hydrazine 20

A mixture of 1 (0.01 mol) and hydrazine hydrate $(0.03 \mathrm{~mol})$ was fused on a hot plate at $100-120{ }^{\circ} \mathrm{C}$ for half an hour, then adding ethanol $(25 \mathrm{~mL})$. The reaction mixture was heated under reflux for $2 \mathrm{~h}$, then poured into ice water and acidified with hydrochloric acid $(1 \mathrm{~N})$. The crude product obtained was filtered off, washed with water, dried and purified by crystallization from ethanol to give 20 as white crystals, in yield $78 \%$, m.p $84-86{ }^{\circ} \mathrm{C}$. ${ }^{1} \mathrm{H}-\mathrm{NMR}$ (DMSO- $d_{6}$ ): $\delta=7.55(\mathrm{~d}, 4 \mathrm{H}, J=8.5 \mathrm{~Hz}, 4 \mathrm{CH}$ ), $7.47(\mathrm{~d}, 4 \mathrm{H}, J=8.5 \mathrm{~Hz}, 4 \mathrm{CH})$ and $2.00\left(\mathrm{~s}, 6 \mathrm{H}, \mathrm{CH}_{3}\right) \mathrm{ppm}$. ${ }^{13} \mathrm{C}$-NMR $\quad\left(\right.$ DMSO- $\left.d_{6}\right): \quad \delta=140.82 \quad(2 \mathrm{C}=\mathrm{N}), \quad 139.04$, 131.00, 126.77, 120.01 (C-aromatic) and $11.19\left(2 \mathrm{CH}_{3}\right)$ ppm. MS: m/z (\%): 394 (33), $393\left(\mathrm{M}^{+},{ }^{79} \mathrm{Br}, 9\right), 395\left(\mathrm{M}^{+}\right.$, $\left.{ }^{81} \mathrm{Br}, 8\right)$ and 55 (100). Anal. Calcd. $\mathrm{C}_{16} \mathrm{H}_{14} \mathrm{Br}_{2} \mathrm{~N}_{2}$ (394.10): C, 48.76; H, 3.58; Br, 40.55; N, 7.11. Found. C, 48.82; H, 3.62; Br, 40.39; N, 7.05.

\section{Cytotoxicity Assay}

In 96-well plate, the cells were seeded at a cell concentration of $1 \times 10^{4}$ cells per well in $100 \mu \mathrm{L}$ of growth medium. Different concentrations from the tested sample in fresh medium were added after $24 \mathrm{~h}$ of seeding. The tested compounds underwent serial two-fold dilutions, then added to confluent cell monolayers dispensed into 96-well, flat-bottomed microtiter plates (Falcon, NJ, USA) using a multichannel pipette. For a period of $48 \mathrm{~h}$, the microtiter plates were incubated in a humidified incubator with $5 \% \mathrm{CO}_{2}$ at $37{ }^{\circ} \mathrm{C}$. For each concentration of the samples, three wells were used. Control cells were incubated without test sample and with or without DMSO. After incubation of the cells at $37{ }^{\circ} \mathrm{C}$, various concentrations of the sample were added, and the incubation was continued for $24 \mathrm{~h}$ and viable cells yield was determined by a colorimetric method.

In brief, media were aspirated and the crystal violet solution (1\%) was added to each well for at least $30 \mathrm{~min}$ after the end of the incubation period. All excess stain is removed, where the plates were rinsed using tap water. To all wells, glacial acetic acid (30\%) was then added and mixed thoroughly, and then the absorbance of the plates was measured after gently shaken on the Microplate reader (TECAN, Inc.), using a test wavelength of $490 \mathrm{~nm}$. All results were corrected for background absorbance detected in wells without added stain. Treated samples were compared with the cell control in the absence of the tested compounds. All experiments were carried out in triplicate. The cell cytotoxic effect of each tested compound was calculated. The optical density was measured with the microplate reader (Sunrise, TECAN, Inc, USA) to determine the number of viable cells and the percentage of viability was calculated as $[1-(\mathrm{ODt} / \mathrm{ODc})] \times 100 \%$ where ODt is the mean optical density of wells treated with the tested sample and ODc is the mean optical density of untreated cells. The relation between surviving cells and drug concentration is plotted to get the survival curve of each tumor cell line after treatment with the specified compound. The $50 \%$ inhibitory concentration $\left(\mathrm{IC}_{50}\right)$, the concentration required to cause toxic effects in $50 \%$ of intact cells, was estimated from graphic plots of the dose-response curve for each conc. using Graphpad Prism software (San Diego, CA. USA).

\section{Additional file}

Additional file 1. Supplimentary materials (spectroscopic data).

\section{Authors' contributions}

HAE designed the research and all authors performed the research, analyzed the data and HAE wrote the final manuscript. All authors read and approved the final manuscript.

\section{Author details}

${ }^{1}$ Department of Chemistry, Faculty of Applied Sciences, Umm Al-Qura University, P. O. Box 13401, Makkah 21955, Saudi Arabia. ${ }^{2}$ Department of Chemistry, Faculty of Science, Al-Azhar University (Girls Branch), P.O. box 11754, Youssef Abbas Str., Cairo, Egypt. ${ }^{3}$ Department of Chemistry, Faculty of Science, Benha University, Banha, Egypt.

\section{Acknowledgements}

The authors would like to thank King Abdulaziz City for Science and Technology (KACST) for the financial support.

\section{Competing interests}

The authors declare that they have no competing interests.

\section{Availability of data and materials}

All the relevant data supporting the conclusions of this article is included in the article (Additional file 1).

Ethics approval and consent to participate Not applicable.

\section{Publisher's Note}

Springer Nature remains neutral with regard to jurisdictional claims in published maps and institutional affiliations.

Received: 13 February 2018 Accepted: 24 April 2018

Published online: 09 May 2018

\section{References}

1. Gangadhar SH, Ramesh DK, Mahajan SK (2013) Synthesis, characterization and anticonvulsant activity of 3-substituted 2-thiohydantoin derivatives. IJRPC 3:793-796

2. Wilson LJ, Li M, Portlock DE (1998) Solid phase synthesis of 1-aminohydantoin libraries. Tetrahedron Lett 39:5135-5138

3. Zuliani V, Carmi C, Rivara M, Fantini M, Lodola A, Vacondio F, Bordi F, Plazzi PV, Cavazzoni A, Galetti M, Alfieri RR, Petronini PG, Mor M (2009) 5-Benzylidene-hydantoins: synthesis and antiproliferative activity on A549 lung cancer cell line. Eur J Med Chem 44:3471-3479

4. Yoshino H, Sato H, Shiraishi T, Tachibana K, Emura T, Honma A, Ishikura N, Tsunenari T, Watanabe M, Nishimoto A, Nakamura R, Nakagawa T, Ohta M, Takata N, Furumoto K, Kimura K, Kawata H (2010) Design and synthesis of 
an androgen receptor pure antagonist (CH5137291) for the treatment of castration-resistant prostate cancer. Bioorg Med Chem 18:8150-8157

5. Shih CR, Wu J, Liu Y, Liang YC, Lin SY, Sheu MT, Lee WS (2004) Anti-proliferation effect of 5,5-diphenyl-2-thiohydantoin (DPTH) in human vascular endothelial cells. Biochem Pharm 67:67-75

6. El-Sharief AM, Moussa Z (2009) Synthesis, characterization and derivatization of some novel types of mono- and bis-imidazolidineiminothiones and imidazolidineiminodithiones with antitumor, antiviral, antibacterial and antifungal activities. Eur J Med Chem 44:4315-4334

7. Abadi AH, Gary BD, Tinsley HN, Piazza GA, Abdel-Halim M (2010) Synthesis, molecular modeling and biological evaluation of novel tadalafil analogues as phosphodiesterase 5 and colon tumor cell growth inhibitors, new stereochemical perspective. Eur J Med Chem 45:1278-1286

8. Moussa Z, El-Sharief AM, Sh El-Sharief M (2011) Synthesis and characterization of new types of halogenated and alkylated imidazolidineiminothiones and a comparative study of their antitumor, antibacterial, and antifungal activities. Eur J Med Chem 46:2280-2289

9. Azizmohammadi M, Khoobi M, Ramazani A, Emami S, Zarrin A, Firuzi O, Miri R, Abbas Shafiee A (2013) 2H-chromene derivatives bearing thiazolidine-2,4-dione, rhodanine or hydantoin moieties as potential anticancer agents. Eur J Med Chem 59:15-22

10. Kiec'-Kononowicz K, Szyman'ska E (2002) Antimycobacterial activity of 5-arylidene derivatives of hydantoin. II Farmaco 57:909-916

11. Kumar V, Rana H, Sankolli R, Kaushik MP (2012) Novel and efficient protocol for the syntheses of $\mathrm{N}-1$ substituted thiohydantoin and a bicyclothiohydantoin under solvent-free conditions. Tetrahedron Lett 53:2377-2379

12. Yildiz I, Bozdag O (2010) Three-dimensional common-feature hypotheses for hypoglycemic flavonyl-2,4-thiazolidinedione derivatives. Med Chem Res 19:211-219

13. Gallienne E, Muccioli GG, Lambert DM, Shipman M (2008) Microwaveassisted four component reaction for the synthesis of a monothiohydantoin inhibitor of a fatty acid amide hydrolase. Tetrahedron Lett 49:6495-6497

14. Ha YM, Kim JA, Park YJ, Park D, Kim JM, Chung KW, Lee EK, Park JY, Lee JY, Lee HJ, Yoon JH, Moon HR, Chung HY (2011) Analogs of 5-(substituted benzylidene)hydantoin as inhibitors of tyrosinase and melanin formation. Biochim Biophys Acta 1810:612-619

15. Bisquera W, Sumera FC (2011) regenerable antimicrobial polyurethane coating based on $\mathrm{N}$-hydroxymethylated hydantoin. Philipp J Sci 140:207-219

16. Rai N, Kalluraya B, Lingappa B, Shenoy S (2009) Microwave assisted synthesis of some novel pyrimidinons/thions. Indian J Chem 48(B):1431-1434

17. Muccioli GG, Fazio N, Scriba GKE, Poppitz W, Cannata F, Poupaert JH, Wouters J, Lambert DM (2006) Substituted 2-thioxoimidazolidin-4-ones and imidazolidine-2,4-diones as fatty acid amide hydrolase inhibitors templates. J Med Chem 49:417-425

18. Bouabdallah I, M'Barek LA, Zyed A, Ramdani A, Zidane I, Melhaoui A (2006) Anticancer effect of three pyrazole derivatives. Nat Prod Res 20:1024-1030

19. Abadi AH, Eissa AAH, Hassan GS (2003) Synthesis of novel 1,3,4-trisubstituted pyrazole derivatives and their evaluation as antitumor and antiangiogenic agents. Chem Pharm Bull 51:838-844

20. Bonte J (2000) Third generation aromatase inhibitors and inactivators in the treatment and prevention of breast cancer. Eur J Cancer 36:114

21. Lonning PE (1996) Pharmacology of new aromatase inhibitors. Breast 5:202

22. Stepanov Al, Astrat'ev AA, Sheremetev AB, Lagutina NK, Palysaeva NV, Tyurin AY, Aleksandrova NS, Sadchikova NP, Suponitsky KY, Atamanenko OP, Konyushkin JD, Semenov RV, Firgang SI, Kiselyov AS, Semenova MN, Semenov VV (2015) A facile synthesis and microtubule-destabilizing properties of 4-(1H-benzo[d]imidazol-2-yl)-furazan-3-amines. Eur J Med Chem 94:237-251
23. El-Hady HA, Abubshait SA (2015) Synthesis of imidazolinone and benzoxazole derivatives and evaluation of their anticancer activity. Res Chem Intermed 41:1833-1841

24. T'ang A, Lien EJ, Lai MMC (1985) Optimization of the Schiff bases of $N$-hydroxy- $N$-aminoguanidine as anticancer and antiviral agents. J Med Chem 28:1103-1106

25. Edward SL, Matteo MR, Genus JP (1987) Benzimidazole derivatives with atypical anti-inflammatory activity. J Med Chem 30(4):726-729

26. AbdEI-Latif NA, Amr AGE, Ibrahiem AA (2007) Synthesis, reactions, and pharmacological screening of heterocyclic derivatives using nicotinic acid as a natural synthon. Monatsh Chem 138:559-567

27. Mohamed SM, Unis M, El-Hady HA (2006) Synthesis and mass spectral fragmentation patterns of some thiazole and imidazolidine derivatives. Indian J Chem 45B:1453-1462

28. Elhady HA, Al-nathali HS, El-Sayed R (2017) Use of 2-(1-(4-bromophenyl) ethylidene)hydrazinecarbothioamide and 2-(5-chloro-2-oxoindolin3-ylidene)hydrazinecarbothioamide in the syntheses of 2-thiohydantoin, pyrimidine derivatives: evaluation of their antimicrobial activities. Int J Adv Res 5:1716-1725

29. Aly HM, Saleh NM, El Hady HA (2011) Design and synthesis of some new thiophene, thienopyrimidine and thienothiadiazine derivatives of antipyrine as potential antimicrobial agents. Eur J Med Chem 46:4566-4572

30. Elhady HA, Aly HM, Saleh NM (2014) Syntheses and antimicrobial activity of new benzofuran, pyrrole, imidazole and thioxoimidazolidin incorporating antipyrine moiety. Int J Adv Res 2:806-816

31. Hussein EM, Al-Shareef HF, Aboellil AH, Elhady HA (2015) Synthesis of some novel 6'-(4-chlorophenyl)-3, 4'-bipyridine-3'-carbonitriles: assessment of their antimicrobial and cytotoxic activity. Z Naturforsch 70(11):783-795

32. Al-Shareef HF, Elhady HA, Aboellil AH, Hussein EM (2016) Ammonium chloride catalyzed synthesis of novel Schiff bases from spiro[indoline3,4'-pyran]-3'-carbonitriles and evaluation of their antimicrobial and anti-breast cancer activities. SpringerPlus 5:887

33. Alshareef HF, Mohamed HA, Salaheldin A (2017) Synthesis and biological evaluation of new tacrine analogues under microwave irradiation. Chem Pharm Bull 65:732-738

34. Mosmann T (1983) Rapid colorimetric assay for cellular growth and survival: application to proliferation and cytotoxicity assays. J Immunol Methods 65:55-63

35. Vijayan P, Raghu C, Ashok G, Dhanara SA, Suresh B (2004) Antiviral activity of medicinal plants of Nilgiris. Indian J Med Res 120:24-29

36. Gomha SM, Riyadh SM, Mahmmoud EA, Elaasser MM (2015) Synthesis and anticancer activities of thiazoles, 1,3-thiazines, and thiazolidine using chitosan-grafted-poly(vinyl pyridine) as basic catalyst. Heterocycles 91(6):1227-1243

\section{Submit your manuscript to a SpringerOpen ${ }^{\odot}$ journal and benefit from:}

- Convenient online submission

- Rigorous peer review

- Open access: articles freely available online

- High visibility within the field

- Retaining the copyright to your article

Submit your next manuscript at $\boldsymbol{\nabla}$ springeropen.com 